\title{
Individual differences in response to positive and negative stimuli: endocannabinoid-based insight on approach and avoidance behaviors
}

\author{
Daniela Laricchiuta ${ }^{1,2}$ and Laura Petrosini ${ }^{1,3}$ \\ 1 IRCCS Fondazione Santa Lucia, Rome, Italy \\ 2 Department of Dynamic and Clinical Psychology, Faculty of Medicine and Psychology, University "Sapienza" of Rome, Rome, Italy \\ ${ }^{3}$ Department of Psychology, Faculty of Medicine and Psychology, University "Sapienza" of Rome, Rome, Italy
}

\section{Edited by:}

Mikhail Lebedev, Duke University, USA

\section{Reviewed by:}

Takefumi Kikusui, Azabu University, Japan

Jony Sheynin, University of Michigan, USA

Clare Marie Mathes, Baldwin

Wallace University, USA

Mikhail Kalinichev, H. Lundbeck

A/S, Denmark

\section{${ }^{*}$ Correspondence:}

Daniela Laricchiuta, IRCCS

Fondazione Santa Lucia, via del

Fosso di Fiorano 64, 00143

Rome, Italy

e-mail:daniela.laricchiuta@

uniroma1.it
Approach and avoidance behaviors-the primary responses to the environmental stimuli of danger, novelty and reward-are associated with the brain structures that mediate cognitive functionality, reward sensitivity and emotional expression. Individual differences in approach and avoidance behaviors are modulated by the functioning of amygdaloidhypothalamic-striatal and striatal-cerebellar networks implicated in action and reaction to salient stimuli. The nodes of these networks are strongly interconnected and by acting on them the endocannabinoid and dopaminergic systems increase the intensity of appetitive or defensive motivation. This review analyzes the approach and avoidance behaviors in humans and rodents, addresses neurobiological and neurochemical aspects of these behaviors, and proposes a possible synaptic plasticity mechanism, related to endocannabinoid-dependent long-term potentiation (LTP) and depression that allows responding to salient positive and negative stimuli.

Keywords: personality traits, endocannabinoid system, dopaminergic system, reward system, fear system, neuroimaging

\section{INTRODUCTION}

Many different labels have been proposed over the years to cover the definition of approach and avoidance. An ApproachWithdrawal distinction was introduced by Schneirla (1965) that argued that in all organisms the motivation is grounded in overt behavioral actions toward or away from stimuli. Subsequently, Davidson (1992) re-utilizing such a distinction presumed that action tendencies are grounded in differently lateralized cortical activation. In their analysis of emotion, Lang et al. (1997) used an Appetite-Aversion distinction to characterize two brain systems that underlie emotions: Appetite connotes consummatory and approach-oriented tendency, whereas Aversion connotes defensive and avoidance-oriented tendency. On the other hand, Lewin (1935), Miller (1944), and McClelland et al. (1953) conceptualized an Approach-Avoidance distinction in terms of valence-based processes, rather than over behavior. More recently, Elliot and Church (1997), Elliot and Thrash (2002), Elliot (2006), and Elliot (2008) addressed the issue, proffering the Approach-Avoidance distinction that expands the previous Approach-Withdrawal distinction in terms of energization of the behavior by (motivation), or direction of the action toward (behavior), positive stimuli in the case of the approach, and in parallel, energization of the behavior by, or direction of the action away from, negative stimuli in the case of the avoidance. Thus, positive or negative valence of the stimulus is considered the core of Approach-Avoidance distinction. The approach and avoidance behaviors appear to be the primary reactions to novel, rewarding, and dangerous stimuli on which all successive responses are based in order to gain successful adaptation. The approach system is considered a motivational system that activates reward-seeking behavior associated with impulsivity/exploration, whereas the avoidance system is considered an attentional system that promotes appetitive response inhibition or active overt withdrawal (McNaughton and Gray, 2000; Pickering and Gray, 2001; Carver and Miller, 2006).

The approach and avoidance behaviors are biologically based and constitutionally ingrained, since all organisms, following a phylogenetic gradient, are "preprogrammed" to approach or avoid particular classes of stimuli (Elliot, 1999, 2005, 2008; Elliot et al., 2006). The phylogenetically early mechanisms engender low-level responses to concrete stimuli, and complex mechanisms mediate sophisticated responses to a broader range of stimuli (Elliot et al., 2006). Approach and avoidance behaviors have been described not only across but also within phyla. Within the same species, some individuals have a greater tendency to approach or avoid a stimulus, also in relation to the age and context. For example, both in humans and animals, very young individuals are more sensitive than adults to the experiences linked to approach and avoidance, as early socialization or desensitization (Rothbart and Bates, 1998; Jones and Gosling, 2008; Sullivan et al., 2008). The adolescents exhibit emotional lability, impulsivity and proclivity to seek rewards and novel 
sensations (Fairbanks, 2001; Spear, 2002; Adriani and Laviola, 2004; Hefner and Holmes, 2007; Good and Radcliffe, 2011), even if sometimes these tendencies are maintained in adulthood (Roberts et al., 2001; Henderson and Wachs, 2007; Krishnan et al., 2007). However, increased sensitivity to reward is reversed in adolescents who are characterized in early childhood as having a behaviorally inhibited temperament (Helfinstein et al., 2011).

Excessive approach or avoidance behavior can lead to psychopathological disorders, as attention-deficit/hyperactivity disorders, depression and substance abuse on one hand, or anxiety and post-traumatic stress disorders on the other hand (Meyer et al., 1999; Muris et al., 2001; Kasch et al., 2002; Mitchell and Nelson-Gray, 2006). Thus, individual differences in approach and avoidance may represent predictors of vulnerability (or resilience) to neuropsychiatric diseases. Many of these conditions show sex differences in age of onset, risk, prevalence and symptomatology (Lynch et al., 2002; Costello et al., 2003; Rutter et al., 2003; ZahnWaxler et al., 2008). In adolescence and adulthood, testosterone might increase susceptibility for some neuropsychiatric conditions by tipping the balance between approach and avoidance. For example, testosterone decreases avoidance by attenuating unconscious fear-responses (Hermans et al., 2006, 2007) and reducing sensitivity to punishment (van Honk et al., 2004), as well as it increases approach by enhancing sensation- and reward-seeking behaviors (van Honk et al., 2004; Coates and Herbert, 2008) and motivation to act (Campbell et al., 2010; Bos et al., 2012). The females exhibit a prolonged avoidance duration in a computerbased approach-avoidance task (Sheynin et al., 2014a,b). However, females may have a higher propensity for cocaine-induced approach-avoidance conflict (Back et al., 2005; Zakharova et al., 2009). In particular, the behavioral effects of drug rewarding stimuli vary across the reproductive cycle with specific "at risk" phases in respect to reward seeking. For example, women report higher drug-induced pleasure during the follicular phase than during the luteal phase (Evans et al., 2002), and female rats display greater reward-seeking behavior during estrus compared to other cycle phases (Feltenstein and See, 2007; Kerstetter et al., 2008, 2013).

\section{CONCEPTUAL SPACE OF APPROACH AND AVOIDANCE BEHAVIORS}

Motivation is based on an intricate array of active approach and avoidance mechanisms. Functionally, approach and avoidance motivation are viewed as instigators of valenced propensities. They influence immediate affective, cognitive, and behavioral inclinations in response to real or imagined stimuli and orient individuals consistently across domains and situations. In humans, although some actions may derive directly and invariably from these proclivities, the ultimate behavior may be self-regulated and subjected to strategic planning, so that individuals can override their initial inclinations and redirect behavior (e.g., putting an approach behavior into action to override a basic avoidance tendency). The separate systems for approaching incentives and avoiding threats show individual differences and are sustained by disparities in brain structure and function. Personality traits are linked to neurobiological measures, such as neurotransmitter metabolites (Cloninger, 1986, 1987; Limson et al., 1991; Cloninger et al., 1993; Kim et al., 2002), markers that are associated with in vivo neuroimaging (Sugiura et al., 2000; Canli et al., 2001; Youn et al., 2002; Kumari et al., 2004), and morphometry (cortical thickness and volumes) in specific brain regions (Yamasue et al., 2008; Gardini et al., 2009; DeYoung et al., 2010; Picerni et al., 2013; Laricchiuta et al., 2014b,c,d). Approach and avoidance are related to and distinct from the central constructs of personality related in turn to the trait adjective, affective disposition, and motivational system constructs (Gable et al., 2003; Quilty and Oakman, 2004).

Trait adjective includes extraversion and neuroticism. Extraversion is the tendency to be sociable, active, optimistic, and to have high sensitivity to positive stimuli. Conversely, neuroticism is the tendency to be worrisome, prone, emotionally unstable, insecure, and to have high sensitivity to negative stimuli (Eysenck, 1981; Costa and McCrae, 1992). The specific sensitivity to positive or negative stimuli affects perceiving, attending, thinking, encoding, and recalling such stimuli. Eysenck (1981) proposed that extraversion is linked to a general cortical "arousability" and that neuroticism correlates with a low threshold for activation in the limbic system. In accordance, Eisenberger et al. (2005) suggested that neuroticism is the result of a neural system that detects a mismatch between actual and expected situations - a function that is carried out by the dorsal anterior cingulate cortex. DeYoung et al. (2010) reported that neuroticism covaries positively with the volume of the cingulate gyrus and negatively with the volume of the dorsomedial prefrontal cortex and posterior hippocampusregions that are associated with threat, punishment, and negative affect. Recent results have shown that cerebellar white matter (WM) and gray matter (GM) volumes negatively covary with neurotic personality traits (Schutter et al., 2012). In parallel, extraversion covaries positively with the volume of the medial orbitofrontal cortex, which mediates the processing of rewardrelated information (DeYoung et al., 2010). Further, a positive association between patterns of synchronous neuronal activity and extraversion has been described in the cerebellum (Wei et al., 2011).

Affective disposition includes positive and negative emotionality, i.e., the tendency to experience positive or negative emotion and engage life in a positive or negative manner, respectively (Tellegen, 1985; Digman, 1990). Whereas positive emotionality is related to approach motivation and is elicited by appetitive stimuli (hedonic stimuli, reward cues, safety signals), negative emotionality is associated with avoidance motivation and is elicited by aversive stimuli (negative stimuli, threat cues, punishment signals). Individuals with high positive emotionality exhibit high energy, optimism, and openness toward others and the future. They tend to focus on the pleasant characteristics of themselves and others. Individuals with high negative emotionality exhibit high levels of distress, anxiety, irritability, fear, pessimism about the future, and dissatisfaction. They call attention to their own unpleasant characteristics and those of others. Electroencephalographic recordings revealed that positive and negative emotionality is associated with left 
and right prefrontal cortex activation, respectively (Wheeler et al., 1993). The link between the extraversion/neuroticism and the positive/negative emotionality is often discussed with regard to emotional reactivity. Extraverts and neurotics respond to stimuli with more intense emotions than introverts and non-neurotics. High levels of approach behavior in extraverts often lead to affective benefits. Unlike negative emotionality, which promotes withdrawal behavior, positive emotionality spurs exploratory behavior. The broaden-and-build theory of positive affect by Fredrickson $(2001,2004)$ suggests that once a positive emotionality is experienced, one seeks to expand and continue the experience that encourages the subject to approach novel situations, ideas, and individuals that are related to the object of interest. The author hypothesizes the development of an upward spiral in which positive emotions and the broadened thinking they engender influence one another reciprocally, leading to appreciable increases in emotional well-being over time. Positive emotions may trigger these upward spirals by building resilience and influencing the ways that people cope with adversity. Complementarily, the author hypothesizes a downward spiral in which negative emotionality and the narrowed pessimistic thinking it engenders influence one another reciprocally, leading to ever-worsening mood, till depression.

Motivational system includes behavioral activation system (BAS) and behavioral inhibition system (BIS). The reinforcement sensitivity theory proposes that the BAS produces positive affect and facilitates approach behaviors in response to conditioned appetitive stimuli, whereas the BIS generates negative affect and facilitates avoidance behaviors in response to conditioned aversive stimuli, especially in novel situations (Gray, 1987; Gray and McNaughton, 2000; McNaughton and Corr, 2004, 2014). Recently, Simon et al. (2010) examined the relation between individual differences in reward sensitivity and neural processing during expectation and reception of a reward, by using functional magnetic resonance imaging (MRI) during a monetary incentive delay task. Subjects with a high BAS exhibited greater activation of the ventral striatum during receipt of the reward, and greater activation of the medial orbitofrontal cortex during receipt and omission of the reward, demonstrating that approaching or avoiding reward-related situations have a distinct relationship with neural processing of the reward. Further, even amygdala responses appear to be positively associated with BAS (Beaver et al., 2008). Resting-state functional MRI demonstrated that BIS correlates negatively with the cerebellum and positively with the frontal gyrus (Kunisato et al., 2011). Increased fetal testosterone (FT) predicted increased BAS by biasing caudate, putamen, and nucleus accumbens to be more responsive to positively compared with negatively valenced information (Lombardo et al., 2012). In contrast, FT was not predictive of BIS, suggesting that testosterone in humans may act as a fetal programing mechanism on the reward system and influence behavioral approach tendencies later in life.

Interestingly, human approach-avoidance behavior has been assessed mainly by self-report questionnaires (e.g., Eysenck, 1981; Costa and McCrae, 1992; Cloninger et al., 1993; Taylor and Sullman, 2009), which query the respondent about the type and frequency of behaviors, and assign a score on each answer. Recently, in a human study on approach and avoidance tendencies the individual differences have been assessed on the Sensitivity to Punishment and Sensitivity to Rewards Questionnaire split into four subscales: Punishment that measures avoidance tendencies related to BIS; Impulsivity/Fun-Seeking, Drive, and Reward Responsivity that measure approach tendencies related in turn to BAS (Lombardo et al., 2012). Furthermore, to more directly evaluate avoidance behaviors, in humans several studies have used mild electric shocks (Lovibond et al., 2008, 2013; Delgado et al., 2009), or aversive visual or auditory stimuli (Dymond et al., 2011) as the aversive events that could be avoided. To evaluate approach behaviors, most human studies have employed monetary incentive tasks allowing the analysis of responses occurring during both expectation and receipt of reward or during the omission of reward (Schlund and Cataldo, 2010; Simon et al., 2010). A number of other studies have used the presentation of primary reinforcers, as somatosensory, olfactory or more often pleasant taste stimuli (O'Doherty et al., 2000, 2002). Another line of human studies has considered computer-based tasks (Molet et al., 2006; Schlund et al., 2010; Sheynin et al., 2014a,b), some of which take the form of a videogame, in the idea that even though no negative (e.g., electric shock) or positive (e.g., pleasant taste or money incentive) stimulus is delivered, people are nonetheless motivated to avoid aversive events and to approach rewarding events within the game. In the same vein, recently in a human study on approach-avoidance conflict a computer game was used in which the collection of monetary tokens provided the approach motivation, while the possibility that a virtual predator might wake up and remove all tokens provided a potential threat, and thus the avoidance motivation (Bach et al., 2014).

\section{APPROACH- AND AVOIDANCE-RELATED PERSONALITY TRAITS AND BRAIN STRUCTURAL VARIATIONS}

Within theories of personality, another model directly related to approach and avoidance is that related to the primary basic personality temperament and character traits by Cloninger (Cloninger, 1987; Cloninger et al., 1993). In his temperament and character inventory (TCI), he described four temperamental traits: Novelty Seeking (NS), Harm Avoidance (HA), Reward Dependence (RD), and Persistence (P). Novelty seeking is an approach-related personality trait and refers to the tendency to act. High NS scores reflect a greater tendency toward exploratory activity in response to novelty, impulsive decisionmaking, extravagant approaches to reward cues, and rapid loss of temper. The advantages of high NS are excitability, curiosity, enthusiasm, and quick engagement with anything that is new and unfamiliar. Conversely, its disadvantages are indifference, lack of reflection and intolerance to monotony, anger, inconsistency in relationships, and quick disengagement whenever a wish is frustrated. Harm avoidance is an avoidance-related personality trait and is the tendency to inhibit behaviors, acting with caution and apprehension. High HA scores indicate proclivity to respond intensively to aversive stimuli or signals of punishment or nonrewards, and they lead to pessimistic worry in anticipation of problems, fear of uncertainty, shyness with strangers, and rapid fatigability. The adaptive advantages of high HA are cautiousness 
and careful planning when a hazard is likely. Its disadvantages arise when a hazard is unlikely but still anticipated which leads to maladaptive inhibition and anxiety. Reward dependence is the inclination to maintain ongoing behaviors that have been associated with reinforcement and to express persistence, social attachment, and dependance on approval by others. High RD scores reflect to be tenderhearted, sensitive, dedicated, dependent, and sociable. The adaptive advantage of high $\mathrm{RD}$ is sensitivity to social cues, which facilitates affectionate social relations and genuine care for others. Its disadvantages are related to suggestibility and loss of objectivity, which are frequently encountered with people who are excessively socially dependent. Persistence refers to the ability to maintain arousal and motivation internally in the absence of an immediate external reward. High P scores indicate hard-working, perseverance, ambitiousness, and perception of frustration as a personal challenge. The adaptive advantage of a high $\mathrm{P}$ is the use of behavioral strategies when a reward is intermittent but the contingencies remain stable. Its disadvantages are related to perfectionist perseverance when contingencies change rapidly.

Within the factors that contribute to individual differences, gender influences HA (females have higher HA scores than males), and age influences NS (young subjects have higher NS scores than elders) (Cloninger et al., 1993; Fresán et al., 2011; Westlye et al., 2011). Although individuals with depression (Ono et al., 2002), bipolar mania (Loftus et al., 2008), schizophrenia (Fresán et al., 2007), substance use disorders (Conway et al., 2003), pathological gambling (Martinotti et al., 2006), and anxiety disorders (Kashdan and Hofmann, 2008) have NS or HA scores higher than healthy subjects, NS and HA are clearly nondysfunctional behaviors and contribute to adaptive functioning. Further, NS and HA provide mechanisms to expand the range of stimuli and possibilities, protect one from potentially aversive contexts, supply the appropriate feedback for sculpting the brain and develop interest in specific domains. Structural neuroimaging studies on the regional specificity of brain-temperament relationships have demonstrated that the strength of fiber tracts from the hippocampus and amygdala to the striatum predicts the individual differences in NS (Cohen et al., 2009). Further, NS correlates positively with the volume of the frontal and posterior cingulate cortex; HA is negatively associated with the volume of the orbitofrontal, occipital, and parietal areas; RD correlates negatively with the volume of the caudate nucleus and frontal gyrus; $\mathrm{P}$ has a positive association with the volume of the precuneus, paracentral lobule, and parahippocampal gyrus (Gardini et al., 2009). Negative relationships between HA and anxiety-related traits and volumes of the entire brain (Knutson et al., 2001) and orbitofrontal (DeYoung et al., 2010) and left anterior prefrontal (Yamasue et al., 2008) cortices have been also reported. In parallel, increased HA is linked to decreased micro-structural integrity in widely distributed fiber tracts that include the corticolimbic pathways (Westlye et al., 2011). Furthermore, subjects with low NS and high HA scores have a relatively low striatal dopaminergic receptor density (Montag et al., 2010).

Assuming that the variability in an approach-related personality trait, such as NS, and an avoidance-related personality trait, such as HA, is normally distributed, in a large cohort of healthy subjects of both sexes and a wide age range (18-67 years), we tested the hypothesis that macro- and micro-structural variations in specific brain areas correlated with scores on the TCI temperamental scales (Picerni et al., 2013; Laricchiuta et al., 2014c,d). Region of interest (ROI)-based and voxel-based morphometry (VBM) analyses were used to assess macro-structural organization, and diffusion tensor imaging (DTI) scan protocol was used to evaluate micro-structural organization (Picerni et al., 2013; Laricchiuta et al., 2014b,c,d). Diffusion tensor imaging measures the diffusion of water molecules through tissues, detects microstructural variations in the brain, and provides physiological information that is not available using conventional MRI (Le Bihan, 2007; Basser and Pierpaoli, 2011). The DTI indices that we used were Mean Diffusivity (MD) for GM and Fractional Anisotropy (FA) for WM, which reflect with great accuracy in space and time the subtle changes in cell structure which accompany various physiological and pathological states. In particular, low values in MD or high values in FA indicate high integrity and efficiency, and advanced organization of brain micro-structure. Variations in water diffusion parameters are linked to variations in cognitive functions (Piras et al., 2010, 2011) and personality dimensions (Westlye et al., 2011; Bjørnebekk et al., 2012, 2013).

We found that increased volumes of the bilateral caudate and pallidum were associated with higher NS scores (Figure 1A), and increased MD measures in the bilateral putamen correlated with higher HA scores (Laricchiuta et al., 2014c). Further, greater cerebellar volumes were linked to higher NS scores, and reduced cerebellar volumes were associated with higher HA scores (Laricchiuta et al., 2014d; Figure 1B). These associations were observed in the cerebellar WM and cortex of both hemispheres. A greater-than-average volume might reflect greater-than-average power to perform specific functions. Human and animal evidence favors the larger-is-more-powerful position: training on particular tasks or experiencing complex environment increases the volume of functionally related brain structures (Boyke et al., 2008; Pangelinan et al., 2011; Di Paola et al., 2013). Thus, it is reasonable to assume that volume tends to covary positively with function. We also noted positive associations between the volumes of vermian lobules VIIb, VIII, and Crus 2 and NS scores (Figure 2; Picerni et al., 2013). The relationship between NS scores and cerebellar structures was also observed at the micro-structural level, as evidenced by the DTI data. The triad including increased volume, decreased $\mathrm{MD}$, increased FA indicates that the macroand micro-structural features of the posterior vermis support approach behaviors.

These novel data that implicate a cerebellar substrate for approach- and avoidance-related personality traits extend the relationship between brain areas and personality to a structure that, until now, was believed to be involved primarily in motor and cognitive functions (Oliveri et al., 2007; Torriero et al., 2007; De Bartolo et al., 2009; Foti et al., 2010; Cutuli et al., 2011; Hampe et al., 2013), much less in emotional processes (Schmahmann and Sherman, 1998; Schmahmann et al., 2007; Timmann and Daum, 2007) and even less in personality individual differences (O'Gorman et al., 2006). Anatomo-clinical analyses indicate that 
A

BASAL GANGLIA
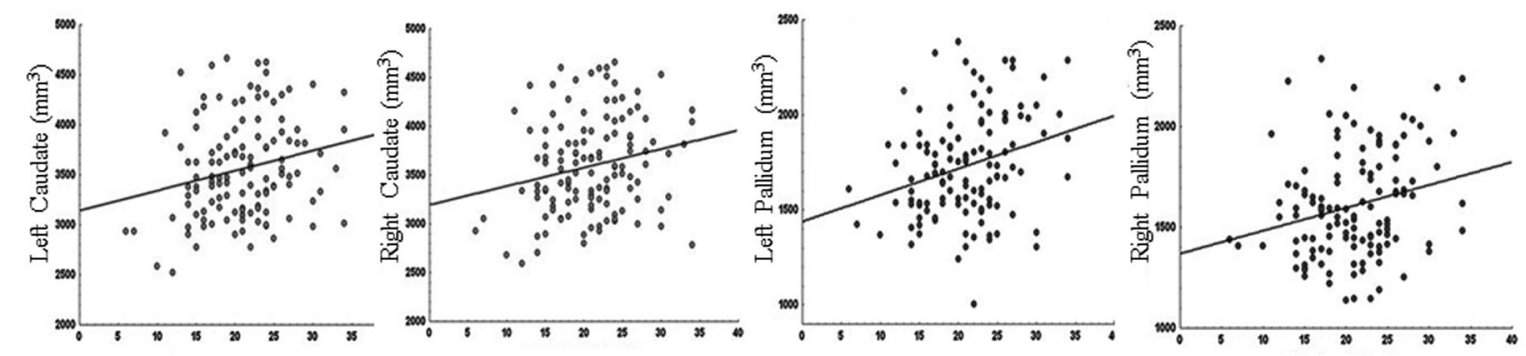

B TCI-NS

TCI-NS

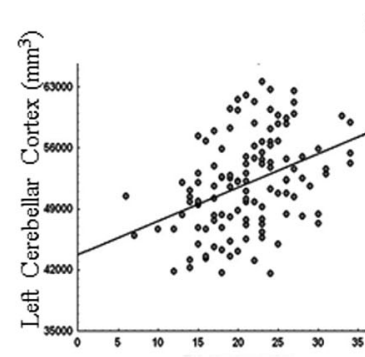

TCI-NS

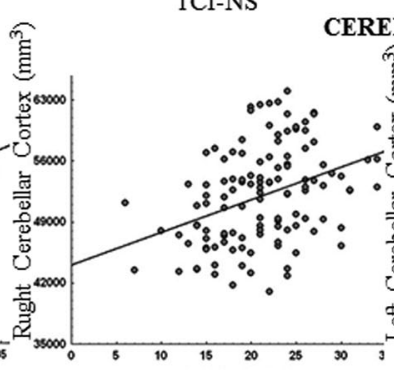

TCI-NS

\section{CEREBELLUM}

TCI-NS

TCI-NS

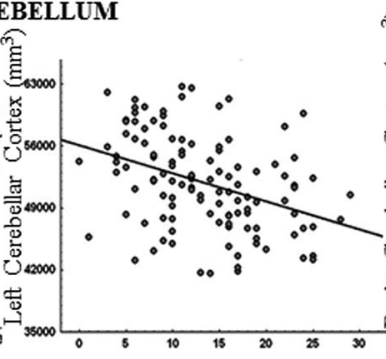

TCI-HA

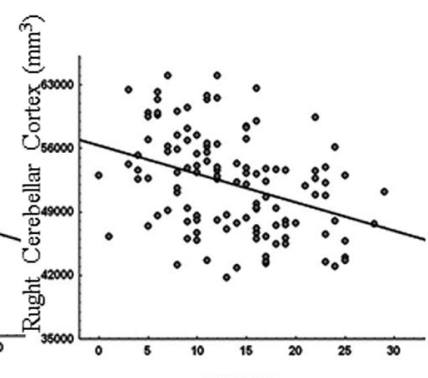

TCI-HA
FIGURE 1 | Relationship between basal ganglia and cerebellar volumes and $\mathrm{TCl}$ scores. (A) The volumes of the bilateral caudate and pallidum were positively associated with Novelty Seeking (NS) scores. (B) The volumes of the cerebellar cortex were positively associated with NS scores and negatively with Harm Avoidance (HA) scores. Scatterplots are separated for left and right volumes. Linear fits (solid black lines) are reported.

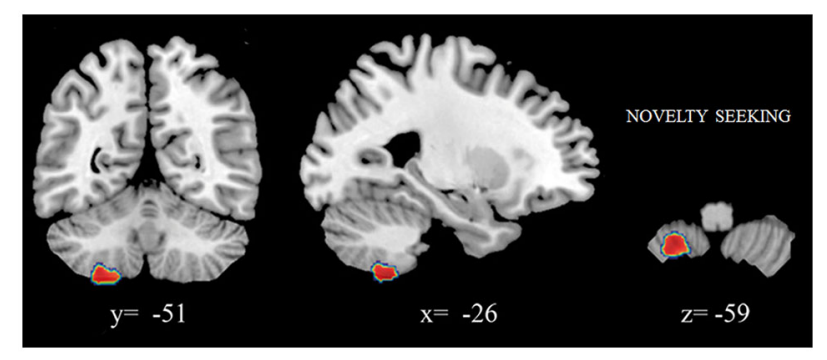

FIGURE 2 | Positive association between cerebellar gray matter volumes and NS scores. Coordinates are in Montreal Neurological Institute (MNI) space. In figure left is left.

the cerebellum is a critical neuromodulator of intellect and mood and that the posterior vermis, the so-called limbic cerebellum, chiefly regulates emotion and affect (Schmahmann, 2004; Stoodley and Schmahmann, 2010; Stoodley et al., 2012). Impaired executive and spatial functions, language deficits, and personality changes have been described in subjects with lesions of the posterior lobe and vermis (cerebellar cognitive-affective syndrome) (Schmahmann and Sherman, 1998). MRI studies have shown structural and functional abnormalities in the cerebellum in patients with personality, anxiety, or depression disorders (Pillay et al., 1997; De Bellis and Kuchibhatla, 2006; Fitzgerald et al., 2008; Baldaçara et al., 2011a,b). This evidence implicates the cerebellum in affective processing which affects personality characteristics. Moreover, the psychopathological profiles of patients who are affected by cerebellar diseases describe them as impulsive, obsessive, hyperactive, disinhibited, and developing ruminative and stereotypical behaviors - features that affect their personality style (Schmahmann et al., 2007). Even data in healthy subjects indicate limited capacity for emotional regulation after repetitive inhibitory transcranial magnetic stimulation over the cerebellum (Schutter and van Honk, 2009). The direct reciprocal connections between the cerebellum and basal ganglia (Figure 3, dashed black line) (Hoshi et al., 2005; Bostan and Strick, 2010; Bostan et al., 2010) constitute the neuroanatomical basis for the cerebellar influence on reward-related behaviors and motivationrelated information processing - functions that, until now, have been attributed only to the basal ganglia (Wise, 2004; Delgado, 2007; Palmiter, 2008). It is likely that the cerebellum accelerates the "force" with which the reward is experienced (Schmahmann et al., 2007). Cerebellar activity signals when the sensory input differs from memory-driven expectations, provides a sensory prediction error, guides exploratory drive in novel environments, allows a flexible switching among multiple tasks or alternatives, and renders functions faster and more adaptive (Restuccia et al., 2007). The cerebellum performs these functions by refining the rate, rhythm, and force of the behavior and adjusting it for given situations. Essentially, the cerebellum receives information from the cortex and basal ganglia and sends a "corrected" signal back. In particular, based on cerebellar detection of error/novelty, Ito (2008) proposed that in the motor and cognitive domains the cerebellum develops both forward and inverse models. In the forward model, the cerebellum is informed by the cortex and basal ganglia with regard to information load, plans, and intentions about the upcoming behavior and on the characteristics of the 


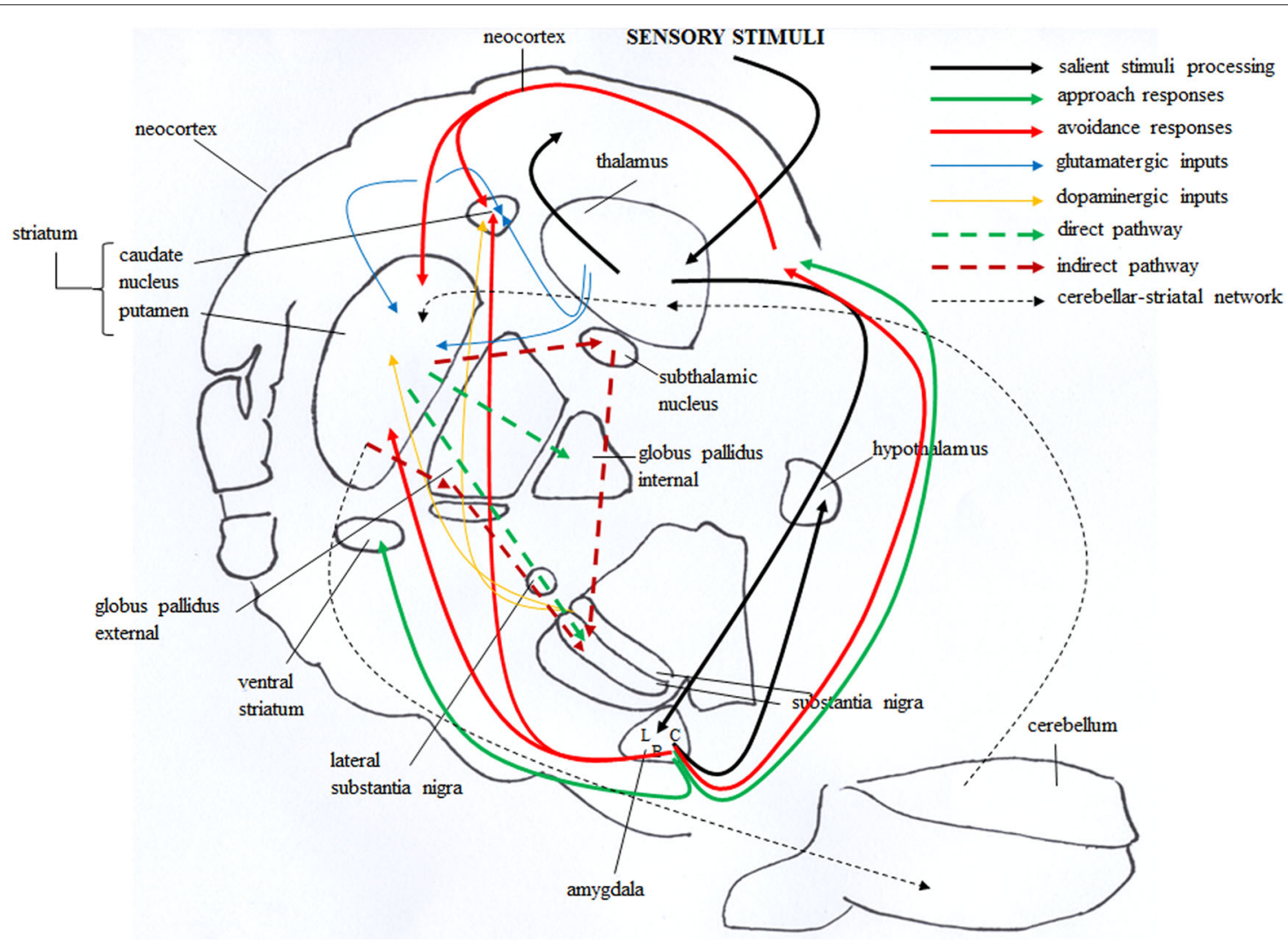

\section{FIGURE 3 | Brain circuitries that mediate approach and avoidance}

behaviors. Salient stimuli information from the sensory systems reaches the thalamus that in turn projects to neocortex and amygdala, first to its lateral (L) and then to central (C) and basal (B) nuclei (solid black line). The amygdala in turn projects to the hypothalamus, and directly or indirectly (via orbitofrontal cortex) to the dorsal striatum. These connections are involved in avoidance responses (solid red line). The outputs from the amygdala also reach the ventral striatum and the orbitofrontal cortex, and these connections are involved in approach responses (solid green line). The dorsal striatum receives also glutamatergic inputs (solid blue line) from neocortical and thalamic areas and dopaminergic inputs (solid yellow line) from the substantia nigra. These inputs establish synapses with striatal GABAergic cells, distinct in "direct" (dashed green line) and "indirect" (dashed red line) pathway projection neurons. Direct pathway projects to the internal globus pallidus and substantia nigra, whereas indirect pathway projects to the substantia nigra by way of the external globus pallidus and subthalamic nucleus. Also the bidirectional striatal-cerebellar network (dashed black line) is involved in the emotional and motivational processes linked to approach and avoidance. environment in which the behavior is manifested. Thus, the cerebellum develops a progressive, short-cut, anticipatory model (Wymbs and Grafton, 2009; Seidler, 2010; van Schouwenburg et al., 2010). As the behavior and cognition are repeated and the anticipatory predicted feedback is received, the cerebellum becomes increasingly accurate in its predictive capacities and allows behavior to become faster, more precise, and independent of cortical control. With successful repetitions, behavior that is governed consciously by the cerebellar forward model becomes increasingly automated and the cerebellar "inverse" model is developed. This permits rapid and skilled behavior to occur at an unconscious level. The cerebellum is constantly constructing multipairs of models that constitute a complex modular architecture for adaptively regulating motor, cognitive, and emotional material. In triggering the new mental activity, the cerebellum could warn the prefrontal cortex about the absence of internal models that match the novel information, maintain the newly generated internal models, and incorporate them into routine schemes of thought. To successfully manage novelty, the cerebellum and neocortical/subcortical areas must be co-activated. Timing, prediction, and learning properties of the cerebellum, once integrated in the circuits that are formed with the neocortex, basal ganglia, and limbic system (Figure 3), could affect the control of complex novelty-related functions (D'Angelo and Casali, 2013). Thus, this widespread two-way communication sustains basal ganglia and cerebellar involvement in motor functions and cognitive and behavioral processing. Cortico-basal-cerebellar communication may influence and sustain even processes that are linked to individual differences in approach and avoidance behaviors (Figure 3, dashed black line). The basal ganglia and cerebellum have complementary roles in facilitating motivation that sustains and reinforces personality features. The positive correlation between basal ganglia and cerebellar volumes and NS scores and the negative association between basal ganglia and cerebellar volumes and HA scores are consistent with the varying levels of engagement that subjects with various personality traits require to their subcortical circuitries. In fact, subjects who search for unfamiliar situations, make the unknown known, explore new environments, display increased tendency toward risk-taking, sensation-seeking, and 
immediate reward-seeking, lack inhibition, as novelty seekers do, need very rapid detection of unfamiliar events, flexible switching among tasks, alternatives, and contexts, and fast adaptation to change. All these functions heavily engage basal ganglia and cerebellum.

\section{APPROACH AND AVOIDANCE BEHAVIORS IN ANIMALS}

It is still very difficult to study the brain mechanisms of human subjective experience like emotion or motivation. Although the neuroimaging techniques are rapidly advancing, they reveal little about the precise working of neurons and trafficking of molecules in the brain activity related to approach and avoidance. Further, neuroimaging studies are correlative and cannot deliver answers about the nature and cause of the associations between structure and function. The techniques required to detail the mechanisms of brain functions usually cannot be used with humans for ethical and practical reasons, but animal research allows for use of these techniques, much as invasive they can be. In the following sections we address the experimental research on approach and avoidance behaviors, facing neurobiological, neurochemical and synaptic aspects.

\section{TOOLS FOR STUDYING APPROACH AND AVOIDANCE BEHAVIORS}

In a wide range of animal species individual differences in approach and avoidance behaviors have been observed, based on direction of the action toward positive (e.g., rewarding) stimuli or away from negative (e.g., dangerous) stimuli, on neophilic or neophobic responses, or on exploratory or withdrawal behaviors (Greenberg, 2003). In an attempt to model in rodents the human individual differences in approach and avoidance behaviors, many behavioral testing paradigms have been employed because almost all behavioral tests encompass approach or avoidance facets. In fact, although most tests are devoted to test spatial, discriminative, mnesic, attentive functions as well as emotional components, in many behavioral tests it is possible to emphasize the component of approach and avoidance. Overall, the tests integrate the approachavoidance conflict designed to promote or inhibit an ongoing behavior characteristic for the animal, such as forcing or vise versa contrasting the tendency of mice to engage in exploratory activity, reward- or novelty-seeking behaviors, and social interaction. Notably, the explorative drive represents the prerequisite to recognize and seek for rewarding or novel stimuli and includes many components, such as suppression of the discomfort caused by unfamiliar spaces, exit from known starting areas, acquisition or use of efficient foraging strategies, and snapshots of the target view and representation-forming procedures.

Among the various tests, the mostly used are the Light-Dark Exploration Test, Social Interaction Test, Novelty-Induced hypophagia test, Approach-Avoidance conflict paradigm, Approach/Avoidance (A/A) Y-maze, and Open Field (OF) test (Bailey and Crawley, 2009).

As for the Light-Dark Exploration Test, the chamber is formed by a cage divided into two unequal compartments by a dark partition with a small aperture located in the bottom center. The smaller compartment is painted black and covered by a hinged lid. The larger compartment is uncovered with transparent sides and is brightly lit by fluorescent room lighting. Thus, the animal is exposed to environment with protected (dark compartment) and unprotected (light compartment) areas. The inherent conflict between exploratory drive and risk avoidance is thought to inhibit exploration. Most mice naturally demonstrate a preference for the dark protected compartment. The key measure for assessing approach-avoidance behavior is a willingness to explore the lighted unprotected area. Such proclivity is reflected in the number of transitions between compartments, and in the time spent in each compartment. An increase in exploratory activity is interpreted as a release of exploratory inhibition and novelty-seeking behavior. In fact, mice exhibiting higher levels of anxiogenic/avoiding-like behavior will make fewer transitions between the brightly illuminated, open area and the dark, enclosed compartment. Further, the time spent in risk assessment is another measure of anxiety/avoidance-related behavior. Risk assessment includes a stretch-attend posture in which the head and forepaws extend into the lighted area but the remainder of the body stays in the dark compartment (Bailey and Crawley, 2009).

As for the Social Interaction Test, unfamiliar animals are allowed to directly or indirectly interact in an arena. Time spent in interacting is recorded. Anxiolytic/approaching-like behavior is inferred if social interaction time increases and general motor activity remains unaffected. Conversely, decreased time spent in engaging social behavior indicates anxiogenic/avoiding-like behavior. The times engaged in aggressive (attack, aggressive unrest), avoiding (vigilant posture, escape and defense activity), approaching (following, social sniffing, over-under climbing) behaviors as well as in motor activities (rearing, walking) are scored (File and Seth, 2003).

Novelty-Induced hypophagia test is based on the typical behavior of the rodents that consume very limited quantities of any new even if highly palatable food and only after considerable investigation. This response is unconditioned, requires no training, and can be elicited in food-deprived or satiated animals by substituting a highly palatable food source for standard food. As the test sessions go on, the latency to the first taste decreases and the total amount of consumed food increases (Dulawa and Hen, 2005).

Approach-Avoidance conflict paradigm consists of a rectangular box subdivided into two compartments. One distinctive visual cue is associated with each compartment: one compartment has white walls and black floor, whereas the other one has black walls and white floor. For three consecutive days, the animal is placed in only one compartment that becomes familiar. In the following days, the animal placed in the familiar compartment is allowed to freely explore the whole apparatus (both familiar and novel compartments). The time spent in each compartment and frequency of crossings between compartments are indices of approach and avoidance behaviors (Adriani et al., 1998; Zoratto et al., 2013).

A/A Y-maze has a starting arm from which two arms stemmed, arranged at an angle of $90^{\circ}$ to each other (Figure $4 \mathrm{~A}$ ). One of the two arms has black and opaque floor and walls and no light inside, while the other one has white floor and walls and is lighted. At the end of each arm of choice there is a food tray. The depth of the tray prevents mice from seeing the reward at a distance 

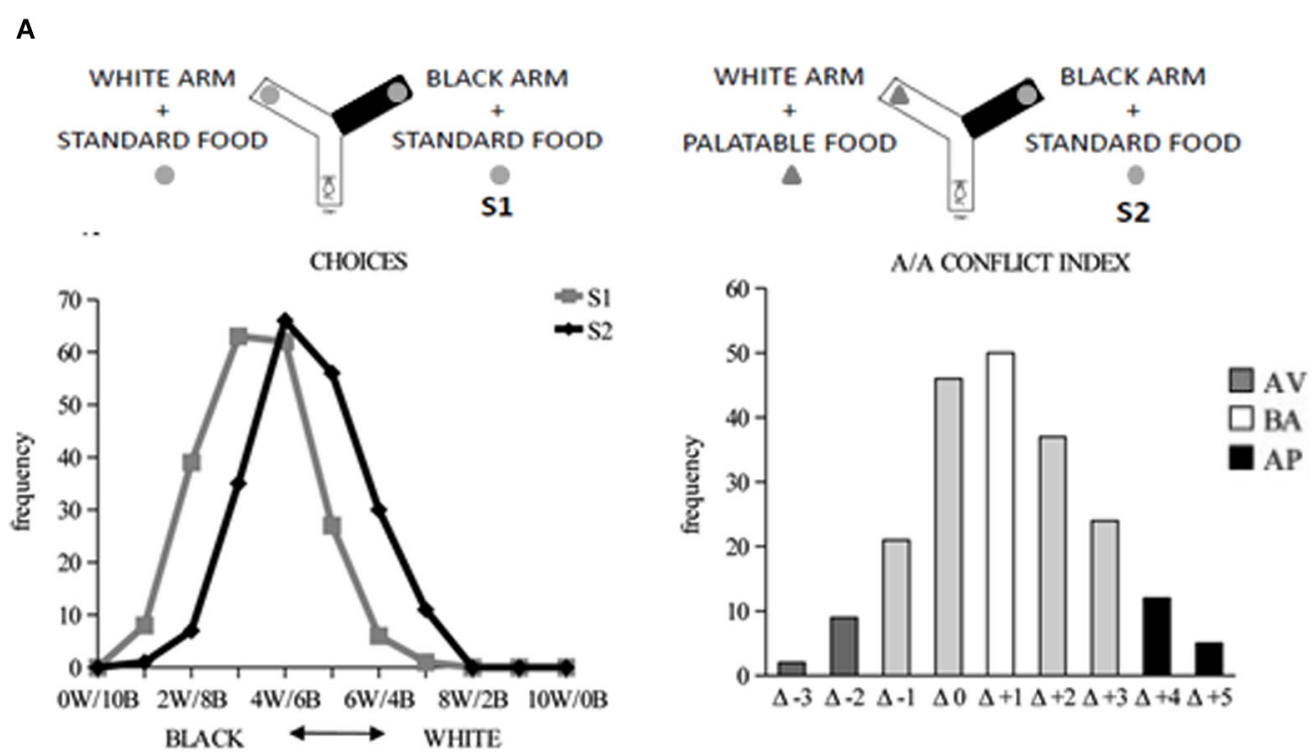

B
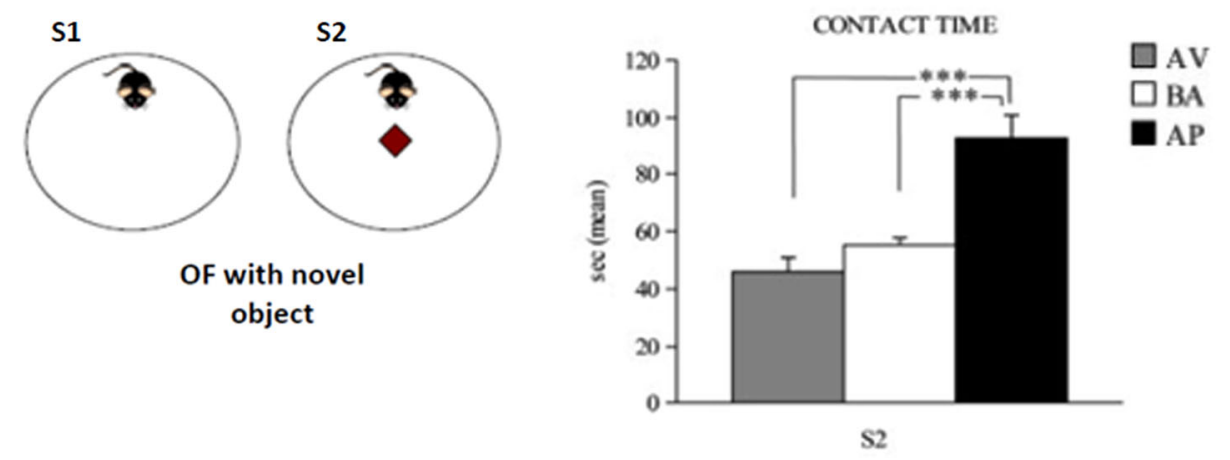

FIGURE 4 | Responses to conflicting stimuli of mice in A/A Y-Maze and OF task. (A) Curves of distribution of the white and black choices of animals during the A/A Y-Maze sessions (on the left). Curve of distribution of the A/A conflict index, considered as the difference $(\Delta)$ in the number of white choices between sessions (on the right). (B) In the OF task (on the right), the

AP mice significantly $(* * * P<0.0005)$ spent more time in contacting the novel object than the AV and BA mice (on the right). Abbreviations: W: white arm; B: black arm; S1: first session; S2: second session; AV: avoiding animals: BA: balancing animals; AP: approaching animals. In (B), data are presented as means \pm SEM.

but allows for an easy reward (eating) and the appreciation of reward scent, not reducing the olfactory cues. Since the appetites for palatable foods have to be learned (Wise, 2006; Lafenêtre et al., 2009), a week before behavioral testing the animals have to be exposed to a novel palatable food (Fonzies, KP Snack Foods, Munchen, Germany) in their home cages for three consecutive days (Bassareo et al., 2002). At the beginning of behavioral testing, mice are subjected to 1-day habituation phase in which all YMaze arms are opened to encourage maze exploration. During habituation phase, no food is present in the apparatus. To increase the motivation to search for the reward, $12 \mathrm{~h}$ before exposure to the experimental set-up, the animals are slightly food deprived by limiting the food access to $12 \mathrm{~h}$ /day. Such a regimen has to result in no significant body weight loss. Testing phase consists of two 10-trial sessions with 1 min-inter-trial interval. In the Session 1 (S1), the mouse is placed in the starting arm and may

choose to enter one of the two arms, both containing the same standard food reward. During the Session 2 (S2; starting $24 \mathrm{~h}$ after $\mathrm{S} 1$ ), the white arm is rewarded with the highly palatable food, while the black arm is rewarded with the standard food pellet. Thus, the A/A Y-maze task requires an animal to choose between two conflicting drives: reaching a new reward (highly palatable food) in an aversive (white and lighted) environment or reaching a familiar food (standard pellets) in a not aversive (black and opaque) environment. The considered parameters were: white choices, the frequency of entry into the white arm in S1 and S2; A/A conflict index, the difference in the number of white choices between S1 and S2; entry latencies exhibited in white and black arms, separately or regardless arm color or reward in each trial of both S1 and S2.

Open field apparatus consists of a wide circular arena delimited by a wall (Figure 4B). In S1, a mouse is allowed to explore 
the empty OF and its baseline level of activity is measured. In S2, the object is put in the arena center. Notably, the approach to the object requires the subject to overcome its innate fear toward open spaces and indicates thus that the animal is reacting to the mismatch between the initial (empty arena) and new (presence of the object) situations. Novelty preference is considered an inverse index of anxiety whereby an anxious mouse tends to avoid the potential dangers associated with a novel and unknown environment. The considered parameters were: total and peripheral distances traveled in the arena; central crossings; freezing duration; number of defecation boluses; latency and time of contact with the object.

In these tasks there is a clear conflict between positive and negative poles that simultaneously evoke approach and avoidance behaviors. Typically, when the positive and negative poles have similar strengths, the subject remains suspended or, at best, gravitates toward the slightly heavier pole of the conflicting situation. Many other tests are devoted to selectively assess behaviors of approach (as drug intake, response to positive conditioned stimulus, brain self-stimulation) or avoidance (as conditioned taste aversion, operant behavior to avoid an electric shock by a leverpress, aversive brain stimulation).

\section{NEUROBIOLOGICAL ASPECTS}

Approach and avoidance behaviors are posited to emerge from mechanisms operative in the spinal cord (Berntson et al., 2003; Schutter et al., 2011), brain stem (Berridge and Peciña, 1995; Nelson and Panksepp, 1998; Challis et al., 2013) and cortex (Nasser and McNally, 2012). Namely, approach and avoidance behaviors are associated with the corticolimbic circuitry that comprises the prefrontal cortex, amygdala, and striatum and that controls cognitive functions, attention, reward sensitivity, and emotional expression (Figure 3; Cain and LeDoux, 2008; LeDoux, 2012; Bravo-Rivera et al., 2014). The intensity of appetitive or defensive motivation-related behaviors are modulated by the levels of neurotransmitters (dopamine, acetylcholine), neuropeptides (corticotrophin-releasing hormone, oxytocin, orexin), and neuromodulators (endocannabinoids) (Robbins and Everitt, 1996; Berridge, 2000; Gerra et al., 2000; Linfoot et al., 2009; Groppe et al., 2013; Mogi et al., 2014). Understanding neurochemical systems is crucial in addressing approach and avoidance topic (Tops et al., 2010). The avoidance situations (satiation, conditioned taste aversion, aversive brain stimulation) have the acetylcholine release in common, while the approach situations (eating, sugar bingeing, drug intake, positive conditioned stimulus, brain self-stimulation) have the dopamine release in common (Hoebel et al., 2007). However, it has to be considered that dopamine is an important factor also in responding to positive punishment provoked by the exposure to an aversive stimulus, and is involved in the motor aspects of both approach and avoidance behaviors. In the nucleus accumbens it has been demonstrated that dopamine and acetylcholine exert opposing roles in the control of GABAergic output in relation to approach and avoidance, and acetylcholine counteracts any excessive approach behavior mediated by the dopamine (Helm et al., 2003; Kelley et al., 2005; Hoebel et al., 2007). Interestingly, adult offspring of dams treated with corticosterone and a tryptophan-deficient diet showed increased avoidance behavior in the approach-avoidance conflict paradigm and anhedonia toward highly palatable reward in an operant progressive ratio test (Zoratto et al., 2013). These behaviors were associated with reduced dopamine and serotonin levels in the prefrontal cortex and reduced striatal and increased hypothalamic Brain Derived Neurotrophic Factor (BDNF) levels. Also neuropeptides are retained to be critical in approach and avoidance behaviors and have been much studied in animal research over the last several years. It has been demonstrated that in odor-recipient rats the odor cues from healthy conspecifics induced approach behavior, while the odor cues from sick conspecifics produced avoidance response (Arakawa et al., 2008, 2009, 2010a, 2011). In the odor-recipient rats, c-Fos mRNA expression was induced in olfactory bulb, amygdala, bed nucleus of stria terminalis, and hypothalamic paraventricular nucleus (Arakawa et al., 2010b). Interestingly, in the amygdala, the expression of oxytocin receptor mRNA was increased when the rats were exposed to healthy conspecific odor, while induction of arginine vasopressin receptor mRNA was found when exposed to sick conspecific odor. Into the amygdala the infusion of an antagonist of oxytocin receptor blocked approach behavior to "healthy" odor, while the infusion of antagonists of arginine vasopressin receptor inhibited avoidance response to "sick" odor. Thus, the approach and avoidance behaviors appear to involve similar brain regions but with different mechanisms (Ikemoto and Panksepp, 1999; Cain and LeDoux, 2008; Nasser and McNally, 2012). Recent findings indicate that also the orexins, hypothalamic neuropeptides that regulate feeding and sleeping behaviors, modulate avoidance behaviors. Rats treated with an antagonist of orexin-1 receptor approached a typically negative stimulus (cat odor) more than vehicle-treated rats (Staples and Cornish, 2014). Notably, exposure to cat odor induced Fos expression in the hypothalamus, suggesting that hypothalamic system is functionally involved with antipredator defensive behaviors (Blanchard et al., 2005). In accordance, microinjections of orexins in the paraventricular thalamic nucleus that innervates the amygdala decreased approach behavior to novelty in rats, indicating a negative emotional state (Li et al., 2010).

A very significant neuromodulatory system on approach and avoidance behaviors in humans (McDonald et al., 2003; Van Laere et al., 2009) as well as rodents (Pattij et al., 2007; Lafenêtre et al., 2009) is the endocannabinoid system (ECS) that deserves a detailed description.

As we recently demonstrated, spontaneous forms of approach and avoidance behaviors rely on ECS modulation in corticolimbic and striatal areas (Laricchiuta et al., 2012b, 2014a,d).

\section{NEUROCHEMICAL ASPECTS: ENDOCANNABINOID AND DOPAMINERGIC SYSTEMS}

After their synthesis from arachidonic acid, endocannabinoids, such as anandamide (AEA) and 2-arachidonoylglycerol (2-AG), modulate synaptic transmission by stimulating cannabinoid type$1\left(\mathrm{CB}_{1}\right)$ receptors (Freund et al., 2003; Piomelli, 2003; Marsicano and Lutz, 2006; Matias and Di Marzo, 2007; Kano et al., 2009). These receptors are primarily expressed in the corticolimbic, striatal and cerebellar pathways (Herkenham et al., 1990; 
Katona et al., 1999; Marsicano and Lutz, 1999; Palmiter, 2008; Koob and Volkow, 2010). Cannabinoid type-1 receptors presynaptically inhibit glutamatergic and GABAergic neurotransmission (Pagotto et al., 2006; Matias and Di Marzo, 2007; Kano et al., 2009) and this inhibitory control of excitatory and inhibitory neuronal subtypes determines the bimodal effects of endocannabinoids (Bellocchio et al., 2010). Thus, the ECS is engaged in myriad of physiological functions. During neural development, the ECS mediates neuronal proliferation, migration, and axonal growth (Berghuis et al., 2007; Harkany et al., 2008; Mulder et al., 2008; Trezza et al., 2008). Throughout life, the ECS influences synaptic transmission, neuroprotection, and neuroinflammation (Fowler and Jacobsson, 2002; Cota et al., 2003; Maldonado et al., 2006; Marsicano and Lutz, 2006; Kano et al., 2009; Lutz, 2009; Fowler et al., 2010). Further, the ECS governs emotional processes, anxiety, stress coping and extinction of aversive memories (Witkin et al., 2005; Lutz, 2007, 2009; Patel and Hillard, 2008; Laricchiuta et al., 2013). The involvement of the ECS in fear extinction is supported by the different responses of the human subjects genotyped for two polymorphisms of $\mathrm{CB}_{1}$ receptors in a fear-potentiated eyeblink startle reflex paradigm (Heitland et al., 2012). In adults with traumarelated psychopathologies, increased $\mathrm{CB}_{1}$ receptor availability in the amygdala is associated with increased attentional bias to threat and increased severity of the symptomatology linked to threat (re-experiencing, avoidance, and hyper-arousal), but not the symptomatology linked to loss (emotional numbing, depression, generalized anxiety) (Pietrzak et al., 2014). Also a common polymorphism that affects the enzymatic degradation of endocannabinoids by fatty acid amide hydrolase (FAAH) is linked to reactivity of the amygdala in relation to threat during a face allocation task involving fearful and angry faces, and to reactivity of the striatum in relation to reward in a gambling task with positive and negative feedback (Hariri, 2009). Further, the individuals with the FAAH polymorphism exhibit quick habituation of amygdala reactivity to threat (Gunduz-Cinar et al., 2013). Thus, the effects of the FAAH polymorphism demonstrate the engagement of ECS in the defensive and appetitive motivational systems (Conzelmann et al., 2012). Moreover, genetic deletion or inhibition of FAAH has context-dependent anxiolytic effects, as demonstrated in mice tested on Elevated Plus-Maze and Light-Dark Exploration Test (Naidu et al., 2007; Moreira et al., 2008).

In mice, experimental manipulations with strong rewarding and reinforcing properties, such as cocaine-induced conditioned place preference, spontaneous running wheel activity, and sucrose consumption, are associated with hypersensitivity of striatal GABAergic synapses to $\mathrm{CB}_{1}$ receptor stimulation (Centonze et al., 2007a,b; De Chiara et al., 2010). Conversely, social defeat chronic stress down-regulates $\mathrm{CB}_{1}$-controlled GABAergic striatal neurotransmission in mice (Rossi et al., 2008). Notably, the reinforcing effects of the primary rewards (food or drug) or the environmental stimuli associated with them enhance the dopaminergic release in corticolimbic and basal ganglia areas (Figure 3, yellow solid line) (Bassareo et al., 2002; Lupica and Riegel, 2005; Alcaro and Panksepp, 2011). Endocannabinoid system and dopaminergic system dynamically interact in controlling neuronal, endocrine, and metabolic responses to reward (Di Marzo et al., 2004; Fernández-Ruiz et al., 2010). In rats, the ECS inhibition on mesolimbic dopaminergic neurons influences the processes of attribution of salience to the reward represented by cocaine and heroin (De Vries et al., 2001; Fattore et al., 2003). The ECS has been implicated in several dopamine-related disorders, such as schizophrenia (Robson et al., 2014), Parkinson's disease (Maccarrone et al., 2003), and drug addiction (Maldonado and Rodríguez de Fonseca, 2002; Rivera et al., 2013; Nader et al., 2014). In these conditions, ECS involvement likely reflects the activity of midbrain dopaminergic neurons and their target structures (Berke and Hyman, 2000; Everitt and Wolf, 2002; Castelli et al., 2011).

To analyze individual differences in spontaneous approach and avoidance behaviors, we tested adolescent (about post-natal day 32nd) C57BL/6JOlaHsd inbred mice in the A/A Y-maze (Laricchiuta et al., 2012b, 2014a,d). In the large sample of mice (more than seven hundred) tested in the A/A Y-maze task, we assigned the individuals into three phenotypes-avoiding ( $\sim 6 \%$ of individuals that spontaneously reacted with withdrawing responses to the conflicting stimuli), balancing ( $25 \%$ of individuals that reacted with balanced responses to the conflicting stimuli), and approaching ( $\sim 7 \%$ of individuals that reacted with advancing responses to the conflicting stimuli, Laricchiuta et al., 2012b, 2014d; Figure 4A). All mice had similar explorativity levels in the initial trials of the task, but only approaching animals maintained high reactivity as trials went by. To eliminate the "food" and "palatability" dimensions and maintain the conflicting drives given by a new object placed in an anxiogenic central location of a wide arena, OF task has been used. In the OF, only the approaching animals were highly explorative and attracted by the new object (Figure 4B; Laricchiuta et al., 2012b). The close relation between approach behavior and explorativity has been proposed also in human studies that report that impulsivity and extraversion (Martin and Potts, 2004; Cohen et al., 2005), and risk aversion and low motivation (Tobler et al., 2007) are related to each other.

Because the A/A Y-maze and OF tasks integrate approachavoidance conflict, the inevitable anxiogenic component that is linked to the conflict had to be considered. No differences in anxiety-related parameters of both tasks (defecation boluses, freezing times and central crossings) were found in the three phenotypes. Also, in the Elevated Plus-Maze, a well-validated anxiety test, all animals had similar anxiety levels.

To analyze the neuronal correlates of the approach and avoidance behaviors displayed by the three sub-populations of animals, we analyzed the $\mathrm{CB}_{1}$-mediated neurotransmission in medium spiny neurons (MSNs) of the dorsomedial striatum that is crucially involved in motivated and goal-directed behaviors (Palmiter, 2008; Koob and Volkow, 2010; Laricchiuta et al., 2012b). Presynaptic control of $\mathrm{CB}_{1}$ receptors on GABAergic transmission in the dorsostriatal MSNs was nearly absent in the avoiding animals but rose increased in the approaching animals. Specifically, application of a $\mathrm{CB}_{1}$ receptor agonist (HU210) to striatal slices provoked peak reductions of $\mathrm{GABA}_{\mathrm{A}}$-mediated inhibitory postsynaptic currents of approximately 40\%, 20\%, and $0 \%$ in approaching, balancing, and avoiding animals, respectively. 
By enhancing the AEA endogenous tone with URB597, a drug that inhibits FAAH, the avoiding animals exhibited increased approach behavior and explorative drive. These behavioral responses were paralleled by the rescue of $\mathrm{CB}_{1}$ receptor sensitivity to HU210. On blocking $\mathrm{CB}_{1}$ receptors with $\mathrm{AM}_{251}$, a $\mathrm{CB}_{1}$ inverse agonist, the approaching animals reduced their contact times with object and explorative behavior in the OF task, behaviors accompanied by complete inhibition of $\mathrm{CB}_{1}$ receptor activity. Thus, the behavioral features of the avoiding and approaching animals treated with ECS agonists and antagonists tended to fade. In a nut shell, the treatment rendered them less inhibited and less "advanced", respectively. These findings were confirmed by counterbalancing the pharmacological manipulations in avoiding and approaching animals. Avoiding animals that had a reduced $\mathrm{CB}_{1}$ control on GABAergic MSNs when further inhibited by AM251 treatment did not display any behavioral as well as electrophysiological modification in comparison to avoiding animals treated with vehicle. In parallel, approaching animals that had an enhanced $\mathrm{CB}_{1}$ control on GABAergic MSNs when further potentiated by URB597 treatment did not display any behavioral as well as electrophysiological modification in comparison to approaching animals treated with vehicle.

Balancing animals treated with URB597 developed a robust approach behavior toward palatable food in the A/A Y-maze and the new object in the OF task (Laricchiuta et al., 2014a). In these animals, the administration of AM251 alone or in combination with URB597 attenuated the approach behavior toward palatable food in the A/A Y-maze and the new object in the OF test, and suppressed the effects of HU210 on dorsostriatal GABAergic MSNs. These findings demonstrate that the effect of URB597 on approach behavior is mediated by $\mathrm{CB}_{1}$ receptors. Notably, in balancing animals, haloperidol (dopaminergic $\mathrm{D}_{2}$ receptor antagonist) blocked their approach behavior toward palatable food in the A/A Y-maze and the new object in the OF task, like AM251 did, and suppressed the effects of HU210 on dorsostriatal GABAergic MSNs (Laricchiuta et al., 2014a). These findings are consistent with the observation that $\mathrm{D}_{2}$ stimulation activates the dorsostriatal ECS, which in turn influences the GABAergic MSNs (Centonze et al., 2004, 2007a,b), and with the disparities in impulsivity that are associated with differences in monoamines in the striatum and nucleus accumbens in inbred rodents (Moreno et al., 2010).

In balancing animals, the co-administration of URB597 and haloperidol counteracted the effects of haloperidol on approach behavior in the A/A Y-maze but not in the OF task. Further, ECS potentiation combined with $\mathrm{D}_{2}$ receptor blockade arose only when the reward was represented by palatable food (Laricchiuta et al., 2014a). Such a facilitatory effect on food reinforcement was due to the higher salience of palatable food, based on the hedonic properties of its palatability, compared with the lower salience of the object, regardless of its novelty. On the electrophysiological level, $\mathrm{CB}_{1}$ receptor sensitivity to $\mathrm{HU} 210$ was rescued when URB597 and haloperidol were co-administered. These findings are consistent with the increased preference for palatable substances (evaluated by sucrose drinking) and sweet taste (evaluated by behavioral and electrophysiological responses to sweet mixtures) that is induced by the administration of exogenous cannabinoids or endocannabinoids (Higgs et al., 2003; Jarrett et al., 2005; Yoshida et al., 2010). In parallel, in rodents the AM251 treatment decreased the palatable food intake (Di Marzo and Matias, 2005; Pagotto et al., 2006). Further, mice injected with the selective $\mathrm{CB}_{1}$ antagonist Rimonabant repeatedly exposed to novel palatable food or a novel object, exhibited decreased reactivity to palatable food intake, but not to novel object (Lafenêtre et al., 2009). Cannabinoid type-1 antagonists decreased and $\mathrm{CB}_{1}$ agonists increased dopamine release induced by rewarding stimuli (Fadda et al., 2006; Solinas et al., 2006). Thus, by regulating the dopaminergic processes the striatal ECS increased the hedonic aspects of food-seeking, evaluated by an operant reinstatement procedure in rats (Duarte et al., 2004). Further, exogenous cannabinoids increased the hedonic reactions to highly palatable food (sucrose) but did not affect the reactions to aversive (quinine and saturated $\mathrm{NaCl}$ solutions) tastes. Consistent with the ability of cannabinoids to increase sucrose palatability, under cannabinoid pretreatment the sucrose induced a release of dopamine in the nucleus accumbens (De Luca et al., 2012).

As previously reported, enhanced or reduced $\mathrm{CB}_{1}$-mediated control on dorsostriatal GABAergic MSNs was associated with spontaneous approach/exploratory or avoidance behaviors, respectively (Laricchiuta et al., 2012b). A possible explanation for this observation could have been that approaching, balancing, and avoiding animals had varying densities of $\mathrm{CB}_{1}$ receptors and disparate activities of FAAH in the brain regions that govern the approach and avoidance behaviors. To test this hypothesis, we measured the density of $\mathrm{CB}_{1}$ receptors (by using $\left[{ }^{3} \mathrm{H}\right] \mathrm{CP} 55,940$ binding autoradiography) and FAAH activity in many brain regions in the three subpopulations of mice (Laricchiuta et al., 2012a). Because significant changes in receptor density do not necessarily translate into gross alterations in receptor functionality or the presence of receptor reserve, we also examined $\mathrm{CB}_{1}$ receptor functionality (by using $\left[{ }^{35} \mathrm{~S}\right] \mathrm{GTP} \gamma \mathrm{S}$ binding autoradiography). Notably, only approaching animals had higher $\mathrm{CB}_{1}$ receptor functionality in the amygdaloid nuclei and hypothalamic dorsomedial nucleus. Interestingly, when compared with balancing animals, both approaching and avoiding animals, which attribute increased motivational salience to stimuli, had greater $\mathrm{CB}_{1}$ receptor densities in the amygdaloid nuclei and hypothalamic ventromedial nucleus. An intriguing parallel on the relation between opposite temperamental traits and similar receptor availability is provided by a PET study that reported the lower availability of striatal dopamine $\mathrm{D}_{2 / 3}$ receptors in healthy subjects with both high or low sensation-seeking, in comparison to subjects with moderate sensation-seeking (Gjedde et al., 2010).

Thus, the subcortical circuit that involves the amygdala and hypothalamus appears to drive individual differences in response to motivational cues, regardless of the opposite direction of the behavioral output. Amygdala mediates the processing of significant stimuli in conditioned fear learning (Pape and Pare, 2010), emotional memory (McGaugh, 2004; LaBar and Cabeza, 2006; LeDoux, 2012), assessment of novel (Schwartz et al., 2003; Weierich et al., 2010), ambiguous (Davis and Whalen, 2001), 
and threatening (LeDoux, 2000; Cain and LeDoux, 2008; Pape and Pare, 2010) stimuli. Further, in the amygdala, $\mathrm{CB}_{1}$ receptors presynaptically inhibit GABAergic neurotransmission (Freund et al., 2003). In theory, in avoiding and approaching animals the decreased inhibitory neurotransmission due to increased $\mathrm{CB}_{1}$ expression could influence the amygdaloid output that converges on other limbic regions, such as the hypothalamus that in turn mediates the reactive component (autonomic and somatic responses) of action. Hypothalamic ventromedial nucleus that regulates ingestive behavior and energy homeostasis exhibits the highest level of $\mathrm{CB}_{1}$ and cannabinoid receptor gene expression (Herkenham et al., 1990; Marsicano and Lutz, 1999; Jamshidi and Taylor, 2001; Pagotto et al., 2006). The increased $\mathrm{CB}_{1}$ density in the hypothalamic ventromedial nucleus in avoiding and approaching animals (and the greater $\mathrm{CB}_{1}$ functionality in the hypothalamic dorsomedial nucleus in approaching animals) could influence their autonomic and somatic responses and affect their phenotypes.

Overall, our data demonstrate that in response to conflicting stimuli, mice exhibit variance of spontaneous behaviors, ranging from avoiding to approaching (Laricchiuta et al., 2012b, $2014 \mathrm{a}, \mathrm{d}$ ). The increased hedonic response and explorative behavior of the approaching animals are linked to greater $\mathrm{CB}_{1}$ mediated control on dorsostriatal inhibitory neurotransmission. Conversely, the inhibitory response to reward of the avoiding animals correlates with decreased $\mathrm{CB}_{1}$-mediated control on dorsostriatal inhibitory neurotransmission. The robust differences among behavioral phenotypes in striatal $\mathrm{CB}_{1}$-mediated currents are not a direct consequence of striatal $\mathrm{CB}_{1}$ receptor expression levels, but they reflect more subtle changes in ECS signaling (Laricchiuta et al., 2012a). In this context, significant evidence indicates that striatal neurotransmission is important for generating anticipatory/preparatory responses in the presence of a conditioned stimulus paired with a positive or negative unconditioned stimulus (Berridge and Robinson, 1998; Ikemoto and Panksepp, 1999; Cardinal et al., 2002).

It has been proposed that the subjects that attribute higher salience to reward-related cues may be vulnerable to addiction (Flagel et al., 2009; Robinson and Flagel, 2009; Saunders and Robinson, 2010), and the subjects that show higher NS behavior may be vulnerable to depressive-like symptoms (Duclot and Kabbaj, 2013). Conversely, the subjects that attribute higher value to aversive cues may be vulnerable to anxiety and post-traumatic stress disorders (Bush et al., 2007; Yehuda and LeDoux, 2007). By using a Pavlovian conditioned approach procedure, Morrow et al. (2011) classified the rats based on whether they learned to approach and interact with a cue that predicted food reward (sign-tracker animals) or conversely learned to go to the location of the food delivery (goal-tracker animals). Sign-trackers were more fearful of discrete cues that predicted foot-shock, while goal-trackers exhibited greater contextual fear even in the absence of discrete cues, suggesting that a subset of individuals attributes high salience to predictive cues regardless of emotional valence. Because motivational systems have evolved primarily to support drives and to direct actions, their outputs facilitate information processing, motor recruitment, action readiness, and affective and attentional engagement.

\section{A POSSIBLE SYNAPTIC SCENARIO OF APPROACH AND AVOIDANCE BEHAVIORS}

As underlined by McNaughton and Corr (2014), the approach and avoidance behaviors have to be anchored to the long-term global sensitivities of the underpinning neural systems. Considering the huge bulk of experimental and human findings (see Elliot, 2008 for an overview), we propose a possible synaptic scenario of approach and avoidance behaviors.

Figure 3 schematizes the main brain structures retained to mediate approach and avoidance behaviors. Information from the sensory systems reaches the thalamus that in turn projects to neocortex and amygdala, first to its lateral and then to its central nucleus (Figure 3, solid black line) (Pape and Pare, 2010). Outputs from the lateral to central and basal nuclei are critical in the increased processing of salient stimuli, whether they are pleasant or aversive (Cain and LeDoux, 2008). The amygdala in turn projects to the hypothalamus (Miguelez et al., 2001). Notably, in the amygdaloid and hypothalamic nuclei the avoiding and approaching animals display an increased density of $\mathrm{CB}_{1}$ receptors (Laricchiuta et al., 2012a). Furthermore, from the amygdala direct or indirect (via orbitofrontal cortex) outputs reach the dorsal striatum and these connections appear to be involved in avoidance responses (Figure 3, solid red line) (Lang and Bradley, 2008). The outputs from the basolateral and central amygdaloid nuclei reach the ventral striatum and the orbitofrontal cortex, and these connections appear to be likely contributors to the execution of approach behavior (Figure 3, solid green line) (Lang and Bradley, 2008). Since both amygdaloid-hypothalamic-striatal and striatal-cerebellar networks are involved in the emotional and motivational processes linked to putting into action behaviors toward or away from emotionally salient stimuli, the striatum that inherently serves as a gating mechanism represents a crucial crossroad in the neuroanatomical geography of approach and avoidance behaviors (McNab and Klingberg, 2008; Koziol et al., 2010). The goal-directed and hedonic nature of the striatal contribution to action is supported by pioneering studies on "compulsory approaching syndrome", in which animals with striatal lesions compulsively followed and contacted humans, other animals, or even stationary objects (Villablanca et al., 1976), and on reinforcing and rewarding effects of striatal micro-stimulations in animals (Plotnik et al., 1972; Phillips et al., 1976, 1979) and humans (Lilly, 1960; Heath, 1963). The dopaminergic nature (Kilpatrick et al., 2000) of the reinforcing and rewarding effects has been conclusively confirmed by recent innovative optogenetic studies (Tsai et al., 2009; Bass et al., 2010; Adamantidis et al., 2011; Witten et al., 2011). Striatal neurons appear to not respond to movement per se but rather to features of the movement that supports reinforcement, such as the anticipation or expected reward value (Kawagoe et al., 1998; Schultz et al., 2000, 2003). However, striatal neurons and dopaminergic release play a role not only in reward processing but also in aversive processing (Ferreira et al., 2003, 2008; Pezze and Feldon, 2004; Matsumoto and Hikosaka, 2009; Bromberg-Martin et al., 2010; Cohen et al., 2012). Roitman et al. (2005) showed that distinct 
A
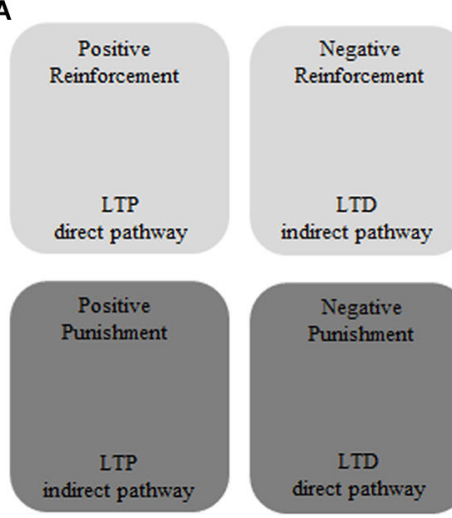

C

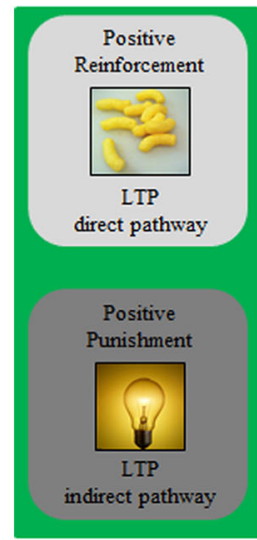

D

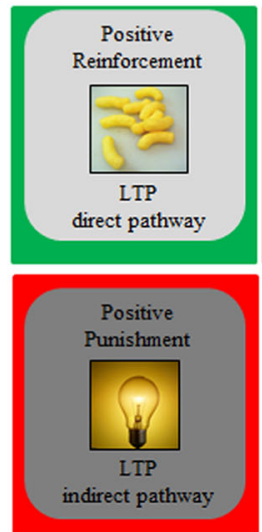

In AP mice $>$ ECS $<$ reversal of LTP
FIGURE 5 | Modeling striatal plasticity of direct and indirect pathways in reinforcement and punishment, related to approach and avoidance. (A) Positive Reinforcement may be associated with LTP onto direct pathway neurons, whereas Positive Punishment may be associated with LTP of indirect pathway neurons. Negative Reinforcement may be associated with LTD onto indirect pathway neurons, whereas Negative Punishment may be associated with LTD of direct pathway neurons. (B) By applying this modeling to the A/A Y-maze task, the Positive Reinforcement is represented by Palatable Food; the Negative Reinforcement by Dark Environment; the Positive Punishment by Lighted Environment; the Negative Punishment by Standard Food. (C) ECS modulations of direct and indirect pathways may
B

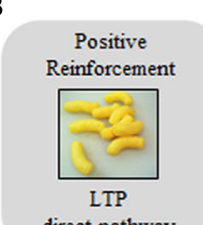

direct pathway
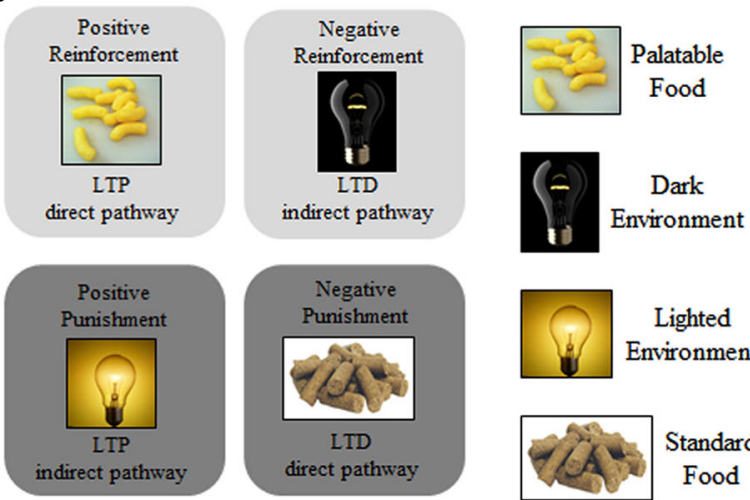

Lighted

Environment

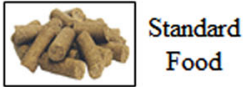

E
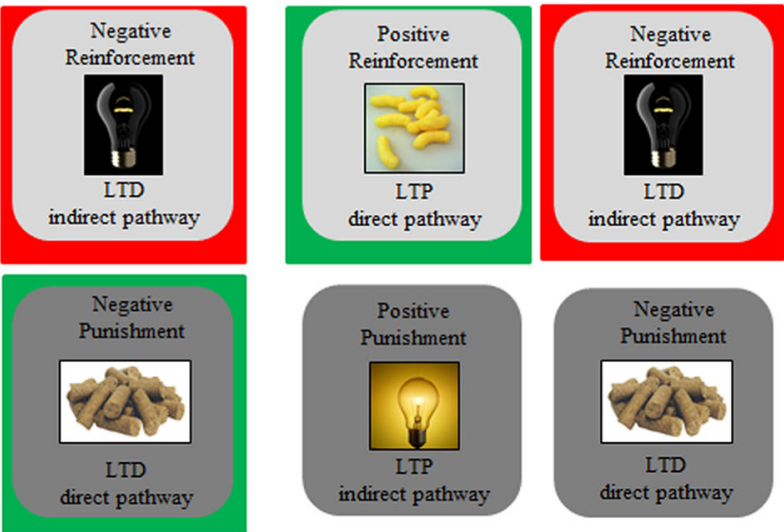

In AV mice $<$ ECS

$>$ LTD

reduce the LTP reversal in the approaching animals, and increase the LTD in the avoiding animals. (D) By modulating the synaptic plasticity, ECS might shift the behavior toward the most significant component of a conflicting context (in the case of approach behavior: Positive Reinforcement against Negative Punishment; in the case of avoidance behavior: Negative Reinforcement against Positive Punishment). (E) By decreasing reversal of LTP, the potentiation of ECS of direct pathway may contribute to the approach behavior, prompting the animal toward the Positive Reinforcement; by increasing LTD, the de-potentiation of ECS of indirect pathway may contribute to the avoidance behavior, prompting the animal toward the Negative Reinforcement.

populations of striatal neurons respond to rewarding (sucrose) or aversive (quinine) taste. Besides the amygdaloid projections, the striatum receives also glutamatergic inputs from neocortical and thalamic areas (Figure 3, solid blue line) and dopaminergic inputs from the substantia nigra (Figure 3, solid yellow line). These inputs establish synapses with striatal GABAergic MSNs and cholinergic interneurons (Calabresi et al., 2014). The MSNs are distinct in "direct" and "indirect" pathway projection neurons (DeLong, 1990; Graybiel et al., 1994). Direct pathway MSNs project to the internal globus pallidus and substantia nigra pars reticulata (SNr; Figure 3, dashed green line), whereas indirect pathway MSNs project to the SNr by way of the external globus pallidus and subthalamic nucleus (Figure 3, dashed red line).
The activation of the direct or indirect pathways facilitates or inhibits the motor output, respectively (Durieux et al., 2009). In this framework, Kravitz and Kreitzer (2012) propose that positive reinforcement (caused by the presence of a positive stimulus) may be associated with plasticity that enhances synaptic efficacy (long-term potentiation, LTP) onto direct pathway neurons, whereas positive punishment (caused by the presence of a negative stimulus) may be associated with LTP of indirect pathway neurons. Conversely, negative reinforcement (caused by the absence of a negative stimulus) may be associated with plasticity that depresses synaptic efficacy (long-term depression, LTD) onto indirect pathway neurons, whereas negative punishment (caused by the absence of a positive stimulus) may be 
associated with LTD of direct pathway neurons (Figure 5A). By applying this interesting schema to the approach-avoidance (A/A Y-Maze) task we used (Laricchiuta et al., 2012b, 2014a,d), the reinforcements and punishments can be labeled as depicted in Figure 5B. Notably, the substrate for the cross-talk between direct and indirect pathways is represented by ECS that induces the LTD of the dorso-striatal MSNs and of their afferent and efferent connections (Lovinger, 2010). However, an opposite synaptic consequence results when the activation of ECS is kept persistent. In fact, in the dorso-striatal MSNs the long-lasting activation of the ECS impairs both LTD and the reversal of LTP (Nazzaro et al., 2012), mechanisms of synaptic plasticity involved in the habit formation (as drug-related habits or compulsive behaviors) and in reinforcement- or reward-related behaviors (Gerdeman et al., 2003; Gerdeman and Lovinger, 2003; Kravitz et al., 2012; Nazzaro et al., 2012). Interestingly, in our approaching or avoiding mice the striatal ECS is potentiated or downregulated, respectively (Laricchiuta et al., 2012b). It is reasonable to hypothesize, although it has been not yet demonstrated, that such ECS modulations may influence the mechanisms of synaptic plasticity, by reducing the LTP reversal in the approaching animals, and by increasing the LTD in the avoiding animals (Figure 5C). The next step of this chained modeling is linked to the rewarding or aversive nature of the direct and indirect pathways. Specifically, are the neurons activated by rewarding stimuli belonging to the direct pathway and the neurons activated by aversive stimuli belonging to indirect pathway? Optogenetic activation of direct or indirect pathway neurons heightens or impairs the strength of cocaine-induced conditioned place preference, respectively (Lobo et al., 2010). Consistently, the activation of direct or indirect pathway neurons heightens or impairs amphetamine sensitization (Ferguson et al., 2011). Furthermore, impaired dopamine-mediated transmission of direct pathway neurons reduces cocaine-locomotor sensitization and impairs conditioned place preference for a food reward, and conversely the impaired transmission of indirect pathway neurons evokes aversive learning deficits (Hikida et al., 2010). Moreover, the stimulation of direct or indirect pathway evokes the rapid learning to contact or to avoid a trigger, respectively (Kravitz et al., 2012), exerting then an opposite control over not just movement, as classically indicated (DeLong, 1990; Graybiel et al., 1994), but also on approach and avoidance behaviors. Thus, in response to the previous questions, it appears that the direct pathway activation is rewarding and indirect pathway activation is aversive. Once more it is possible to hypothesize that by modulating the synaptic plasticity of direct and indirect pathways neurons, the ECS might shift the behavior toward the most significant component of any conflicting context (in the case of approaching behavior: positive reinforcement against negative punishment; in the case of avoiding behavior: negative reinforcement against positive punishment), determining thus the ultimate behavioral outcome (Figure 5D). The further final step of the chained modeling can be performed by integrating the schema by Kravitz and Kreitzer (2012), the findings by Nazzaro et al. (2012) and our own results (Laricchiuta et al., 2012b). We suggest that by decreasing the reversal of LTP the potentiation of ECS on direct pathway might contribute to the approach behavior, prompting the animal toward the positive reinforcement (palatable food). Conversely, by increasing LTD the de-potentiation of ECS on indirect pathway might contribute to the avoidance behavior, prompting the animal toward the negative reinforcement (dark environment) (Figure 5E).

\section{CONCLUSIONS}

Approach and avoidance behaviors are the foundation of emotional and motivational experience. These behaviors are modulated by the functioning of the network encompassing the subcortical structures implicated in the action (amygdala, dorsal striatum, cerebellum) and re-action (amygdala, hypothalamus) to salient stimuli. The nodes of this network are strongly interconnected and the final behavioral output probably depends upon the weight of the various nodes. By acting on them the endocannabinoid and dopaminergic systems increase the intensity of appetitive or defensive motivation (Häring et al., 2011; Fiorillo, 2013; Ohno-Shosaku and Kano, 2014; Piomelli, 2014). Large individual differences in endocannabinoid and dopaminergic transmission at the striatal, limbic and cortical level have been described in animals (Verheij and Cools, 2008; Yamamoto et al., 2013; Coria et al., 2014; Flagel et al., 2014) and humans (Moresco et al., 2002; Van Laere et al., 2009), as if the primitive model of response to salient stimuli is maintained as a "phylogenetic footprinting" that allows survival and adaptation.

\section{AUTHOR'S CONTRIBUTIONS}

Daniela Laricchiuta and Laura Petrosini wrote the paper and revisited it critically for important intellectual content, approving the final version of the paper and agreeing to be accountable for all aspects of the work.

\section{REFERENCES}

Adamantidis, A. R., Tsai, H. C., Boutrel, B., Zhang, F., Stuber, G. D., Budygin, E. A., et al. (2011). Optogenetic interrogation of dopaminergic modulation of the multiple phases of reward-seeking behavior. J. Neurosci. 31, 10829-10835. doi: 10.1523/JNEUROSCI.2246-11.2011

Adriani, W., Chiarotti, F., and Laviola, G. (1998). Elevated novelty seeking and peculiar d-amphetamine sensitization in periadolescent mice compared with adult mice. Behav. Neurosci. 112, 1152-1166. doi: 10.1037//0735-7044.112.5. 1152

Adriani, W., and Laviola, G. (2004). Windows of vulnerability to psychopathology and therapeutic strategy in the adolescent rodent model. Behav. Pharmacol. 15, 341-352. doi: 10.1097/00008877-200409000-00005

Alcaro, A., and Panksepp, J. (2011). The SEEKING mind: primal neuro-affective substrates for appetitive incentive states and their pathological dynamics in addictions and depression. Neurosci. Biobehav. Rev. 35, 1805-1820. doi: 10. 1016/j.neubiorev.2011.03.002

Arakawa, H., Arakawa, K., and Deak, T. (2009). Acute illness induces the release of aversive odor cues from adult, but not prepubertal, male rats and suppresses social investigation by conspecifics. Behav. Neurosci. 123, 964-978. doi: 10 . 1037/a0017114

Arakawa, H., Arakawa, K., and Deak, T. (2010a). Sickness-related odor communication signals as determinants of social behavior in rat: a role for inflammatory processes. Horm. Behav. 57, 330-341. doi: 10.1016/j.yhbeh.2010.01.002

Arakawa, H., Arakawa, K., and Deak, T. (2010b). Oxytocin and vasopressin in the medial amygdala differentially modulate approach and avoidance behavior toward illness-related social odor. Neuroscience 171, 1141-1151. doi: 10.1016/j. neuroscience.2010.10.013 
Arakawa, H., Blanchard, D. C., Arakawa, K., Dunlop, C., and Blanchard, R. J. (2008). Scent marking behavior as an odorant communication in mice. Neurosci. Biobehav. Rev. 32, 1236-1248. doi: 10.1016/j.neubiorev.2008.05.012

Arakawa, H., Cruz, S., and Deak, T. (2011). From models to mechanisms: odorant communication as a key determinant of social behavior in rodents during illness-associated states. Neurosci. Biobehav. Rev. 35, 1916-1928. doi: 10.1016/j. neubiorev.2011.03.007

Bach, D. R., Guitart-Masip, M., Packard, P. A., Miró, J., Falip, M., Fuentemilla, L., et al. (2014). Human hippocampus arbitrates approach-avoidance conflict. Curr. Biol. 24, 541-547. doi: 10.1016/j.cub.2014.01.046

Back, S. E., Brady, K. T., Jackson, J. L., Salstrom, S., and Zinzow, H. (2005). Gender differences in stress reactivity among cocaine-dependent individuals. Psychopharmacology (Berl) 180, 169-176. doi: 10.1007/s00213-004-2129-7

Bailey, K. R., and Crawley, J. N. (2009). "Anxiety-related behaviors in mice," in Methods of Behavior Analysis in Neuroscience. 2nd Edn. ed J. J. Buccafusco (Boca Raton FL: CRC Press), Chapter 5.

Baldaçara, L., Jackowski, A. P., Schoedl, A., Pupo, M., Andreoli, S. B., Mello, M. F., et al. (2011a). Reduced cerebellar left hemisphere and vermal volume in adults with PTSD from a community sample. J. Psychiatr. Res. 45, 1627-1633. doi: 10. 1016/j.jpsychires.2011.07.013

Baldaçara, L., Nery-Fernandes, F., Rocha, M., Quarantini, L. C., Rocha, G. G., Guimarães, J. L., et al. (2011b). Is cerebellar volume related to bipolar disorder? J. Affect. Disord. 135, 305-309. doi: 10.1016/j.jad.2011.06.059

Bass, C. E., Grinevich, V. P., Vance, Z. B., Sullivan, R. P., Bonin, K. D., and Budygin, E. A. (2010). Optogenetic control of striatal dopamine release in rats. J. Neurochem. 114, 1344-1352. doi: 10.1111/j.1471-4159.2010.06850.x

Bassareo, V., De Luca, M. A., and Di Chiara, G. (2002). Differential expression of motivational stimulus properties by dopamine in nucleus accumbens shell versus core and prefrontal cortex. J. Neurosci. 22, 4709-4719.

Basser, P. J., and Pierpaoli, C. (2011). Microstructural and physiological features of tissues elucidated by quantitative-diffusion-tensor MRI. 1996. J. Magn. Reson. 213, 560-570. doi: 10.1016/j.jmr.2011.09.022

Beaver, J. D., Lawrence, A. D., Passamonti, L., and Calder, A. J. (2008). Appetitive motivation predicts the neural response to facial signals of aggression. J. Neurosci. 28, 2719-2725. doi: 10.1523/JNEUROSCI.0033-08.2008

Bellocchio, L., Lafenêtre, P., Cannich, A., Cota, D., Puente, N., Grandes, P., et al. (2010). Bimodal control of stimulated food intake by the endocannabinoid system. Nat. Neurosci. 13, 281-283. doi: 10.1038/nn.2494

Berghuis, P., Rajnicek, A. M., Morozov, Y. M., Ross, R. A., Mulder, J., Urbán, G. M., et al. (2007). Hardwiring the brain: endocannabinoids shape neuronal connectivity. Science 316, 1212-1216. doi: 10.1126/science.1137406

Berke, J. D., and Hyman, S. E. (2000). Addiction, dopamine and the molecular mechanisms of memory. Neuron 25, 515-532. doi: 10.1016/s08966273(00)81056-9

Berntson, G. G., Boyson, S. T., and Cacioppo, J. T. (2003). Neurobehavioral organization and the cardinal principle of evaluation bivalence. Ann. N Y Acad. Sci. 702, 75-102. doi: 10.1111/j.1749-6632.1993.tb17243.x

Berridge, K. C. (2000). Measuring hedonic impact in animals and infants: microstructure of affective taste reactivity patterns. Neurosci. Biobehav. Rev. 24, 173-198. doi: 10.1016/s0149-7634(99)00072-x

Berridge, K. C., and Peciña, S. (1995). Benzodiazepines, appetite and taste palatability. Neurosci. Biobehav. Rev. 19, 121-131. doi: 10.1016/0149-7634(94)00026-w

Berridge, K. C., and Robinson, T. E. (1998). What is the role of dopamine in reward: hedonic impact, reward learning, or incentive salience? Brain Res. Brain Res. Rev. 28, 309-369. doi: 10.1016/s0165-0173(98)00019-8

Bjørnebekk, A., Fjell, A. M., Walhovd, K. B., Grydeland, H., Torgersen, S., and Westlye, L. T. (2013). Neuronal correlates of the five factor model (FFM) of human personality: multimodal imaging in a large healthy sample. Neuroimage 65, 194-208. doi: 10.1016/j.neuroimage.2012.10.009

Bjørnebekk, A., Westlye, L. T., Fjell, A. M., Grydeland, H., and Walhovd, K. B. (2012). Social reward dependence and brain white matter microstructure. Cereb. Cortex 22, 2672-2679. doi: 10.1093/cercor/bhr345

Blanchard, D. C., Canteras, N. S., Markham, C. M., Pentkowski, N. S., and Blanchard, R. J. (2005). Lesions of structures showing FOS expression to cat presentation: effects on responsivity to a cat, cat odor and nonpredator threat. Neurosci. Biobehav. Rev. 29, 1243-1253. doi: 10.1016/j.neubiorev.2005. 04.019

Bos, P. A., Panksepp, J., Bluthé, R. M., and van Honk, J. (2012). Acute effects of steroid hormones and neuropeptides on human social-emotional behavior: a review of single administration studies. Front. Neuroendocrinol. 33, 17-35. doi: 10.1016/j.yfrne.2011.01.002

Bostan, A. C., Dum, R. P., and Strick, P. L. (2010). The basal ganglia communicate with the cerebellum. Proc. Natl. Acad. Sci. U S A 107, 8452-8456. doi: 10. 1073/pnas.1000496107

Bostan, A. C., and Strick, P. L. (2010). The cerebellum and basal ganglia are interconnected. Neuropsychol. Rev. 20, 261-270. doi: 10.1007/s11065-0109143-9

Boyke, J., Driemeyer, J., Gaser, C., Büchel, C., and May, A. (2008). Training-induced brain structure changes in the elderly. J. Neurosci. 28, 7031-7035. doi: 10 . 1523/JNEUROSCI.0742-08.2008

Bravo-Rivera, C., Roman-Ortiz, C., Brignoni-Perez, E., Sotres-Bayon, F., and Quirk, G. J. (2014). Neural structures mediating expression and extinction of platformmediated avoidance. J. Neurosci. 34, 9736-9742. doi: 10.1523/JNEUROSCI. 0191-14.2014

Bromberg-Martin, E. S., Matsumoto, M., and Hikosaka, O. (2010). Dopamine in motivational control: rewarding, aversive and alerting. Neuron 68, 815-834. doi: 10.1016/j.neuron.2010.11.022

Bush, D. E., Sotres-Bayon, F., and LeDoux, J. E. (2007). Individual differences in fear: isolating fear reactivity and fear recovery phenotypes. J. Trauma Stress 20, 413-422. doi: 10.1002/jts.20261

Cain, C. K., and LeDoux, J. E. (2008). "Emotional processing and motivational: in search of brain mechanisms," in Handbook of Approach and Avoidance Motivation, ed A. J. Elliot (New York: Taylor and Francis Group), 17-34.

Calabresi, P., Picconi, B., Tozzi, A., Ghiglieri, V., and Di Filippo, M. (2014). Direct and indirect pathways of basal ganglia: a critical reappraisal. Nat. Neurosci. 17, 1022-1030. doi: 10.1038/nn.3743

Campbell, B. C., Dreber, A., Apicella, C. L., Eisenberg, D. T., Gray, P. B., Little, A. C., et al. (2010). Testosterone exposure, dopaminergic reward and sensationseeking in young men. Physiol. Behav. 99, 451-456. doi: 10.1016/j.physbeh.2009. 12.011

Canli, T., Zhao, Z., Desmond, J. E., Kang, E., Gross, J., and Gabrieli, J. D. (2001). An fMRI study of personality influences on brain reactivity to emotional stimuli. Behav. Neurosci. 115, 33-42. doi: 10.1037//0735-7044.115.1.33

Cardinal, R. N., Parkinson, J. A., Hall, J., and Everitt, B. J. (2002). Emotion and motivation: the role of the amygdala, ventral striatum and prefrontal cortex. Neurosci. Biobehav. Rev. 26, 321-352. doi: 10.1016/s0149-7634(02)00007-6

Carver, C. S., and Miller, C. J. (2006). Relations of serotonin function to personality: current views and a key methodological issue. Psychiatry Res. 144, 1-15. doi: 10. 1016/j.psychres.2006.03.013

Castelli, M., Federici, M., Rossi, S., De Chiara, V., Napolitano, F., Studer, V., et al. (2011). Loss of striatal cannabinoid CB1 receptor function in attentiondeficit/hyperactivity disorder mice with point-mutation of the dopamine transporter. Eur. J. Neurosci. 34, 1369-1377. doi: 10.1111/j.1460-9568.2011. 07876.x

Centonze, D., Battista, N., Rossi, S., Mercuri, N. B., Finazzi-Agrò, A., Bernardi, G., et al. (2004). A critical interaction between dopamine D2 receptors and endocannabinoids mediates the effects of cocaine on striatal gabaergic transmission. Neuropsychopharmacology 29, 1488-1497. doi: 10.1038/sj.npp.1300458

Centonze, D., Rossi, S., De Chiara, V., Prosperetti, C., Battista, N., Bernardi, G., et al. (2007a). Chronic cocaine sensitizes striatal GABAergic synapses to the stimulation of cannabinoid CB1 receptors. Eur. J. Neurosci. 25, 1631-1640. doi: 10.1111/j.1460-9568.2007.05433.x

Centonze, D., Rossi, S., Prosperetti, C., Gasperi, V., De Chiara, V., Bari, M., et al. (2007b). Endocannabinoids limit metabotropic glutamate 5 receptor-mediated synaptic inhibition of striatal principal neurons. Mol. Cell. Neurosci. 35, 302310. doi: 10.1016/j.mcn.2007.03.005

Challis, C., Boulden, J., Veerakumar, A., Espallergues, J., Vassoler, F. M., Pierce, R. C., et al. (2013). Raphe GABAergic neurons mediate the acquisition of avoidance after social defeat. J. Neurosci. 33, 13978-13988, 13988a. doi: 10. 1523/JNEUROSCI.2383-13.2013

Cloninger, C. R. (1986). A unified biosocial theory of personality and its role in the development of anxiety states. Psychiatr. Dev. 3, 167-226.

Cloninger, C. R. (1987). A systematic method for clinical description and classification of personality variants. Arch. Gen. Psychiatry 44, 573-588. doi: 10. 1001/archpsyc.1987.01800180093014

Cloninger, C. R., Svrakic, D. M., and Przybeck, T. R. (1993). A psychobiological model of temperament and character. Arch. Gen. Psychiatry 50, 975-990. doi: 10. 1001/archpsyc. 1993.01820240059008 
Coates, J. M., and Herbert, J. (2008). Endogenous steroids and financial risk taking on a London trading floor. Proc. Natl. Acad. Sci. U S A 105, 6167-6172. doi: 10. 1073/pnas.0704025105

Cohen, J. Y., Haesler, S., Vong, L., Lowell, B. B., and Uchida, N. (2012). Neurontype-specific signals for reward and punishment in the ventral tegmental area. Nature 482, 85-88. doi: 10.1038/nature10754

Cohen, M. X., Schoene-Bake, J. C., Elger, C. E., and Weber, B. (2009). Connectivitybased segregation of the human striatum predicts personality characteristics. Nat. Neurosci. 12, 32-34. doi: 10.1038/nn.2228

Cohen, M. X., Young, J., Baek, J. M., Kessler, C., and Ranganath, C. (2005). Individual differences in extraversion and dopamine genetics predict neural reward responses. Brain Res. Cogn. Brain Res. 25, 851-861. doi: 10.1016/j. cogbrainres.2005.09.018

Conway, K. P., Kane, R. J., Ball, S. A., Poling, J. C., and Rounsaville, B. J. (2003). Personality, substance of choice and polysubstance involvement among substance dependent patients. Drug Alcohol Depend. 71, 65-75. doi: 10.1016/s03768716(03)00068-1

Conzelmann, A., Reif, A., Jacob, C., Weyers, P., Lesch, K. P., Lutz, B., et al. (2012). A polymorphism in the gene of the endocannabinoid-degrading enzyme FAAH (FAAH C385A) is associated with emotional-motivational reactivity. Psychopharmacology (Berl) 224, 573-579. doi: 10.1007/s00213-012-2785-y

Coria, S. M., Roura-Martínez, D., Ucha, M., Assis, M. A., Miguéns, M., GarcíaLecumberri, C., et al. (2014). Strain differences in the expression of endocannabinoid genes and in cannabinoid receptor binding in the brain of Lewis and Fischer 344 rats. Prog. Neuropsychopharmacol. Biol. Psychiatry 53, 15-22. doi: 10.1016/j.pnpbp.2014.02.012

Costa, P. T., and McCrae, R. R. (1992). Revised NEO Personality Inventory (NEOPIR) and Five Factor Inventory (NEO-FFI) Professional Manual. Odessa, FL: Psychological Assessment Resources.

Costello, E. J., Mustillo, S., Erkanli, A., Keeler, G., and Angold, A. (2003). Prevalence and development of psychiatric disorders in childhood and adolescence. Arch. Gen. Psychiatry 60, 837-844. doi: 10.1001/archpsyc.60.8.837

Cota, D., Marsicano, G., Lutz, B., Vicennati, V., Stalla, G. K., Pasquali, R., et al. (2003). Endogenous cannabinoid system as a modulator of food intake. Int. J. Obes. Relat. Metab. Disord. 27, 289-301. doi: 10.1038/sj.ijo.0802250

Cutuli, D., Rossi, S., Burello, L., Laricchiuta, D., De Chiara, V., Foti, F., et al. (2011). Before or after does it matter? Different protocols of environmental enrichment differently influence motor, synaptic and structural deficits of cerebellar origin. Neurobiol. Dis. 42, 9-20. doi: 10.1016/j.nbd.2010.12.007

D'Angelo, E., and Casali, S. (2013). Seeking a unified framework for cerebellar function and dysfunction: from circuit operations to cognition. Front. Neural Circuits 6:116. doi: 10.3389/fncir.2012.00116

Davidson, R. J. (1992). Anterior cerebral asymmetry and the nature of emotion. Brain Cogn. 20, 125-151. doi: 10.1016/0278-2626(92)90065-t

Davis, M., and Whalen, P. J. (2001). The amygdala: vigilance and emotion. Mol. Psychiatry 6, 13-34. doi: 10.1038/sj.mp.4000812

De Bartolo, P., Mandolesi, L., Federico, F., Foti, F., Cutuli, D., Gelfo, F., et al. (2009). Cerebellar involvement in cognitive flexibility. Neurobiol. Learn. Mem. 92, 310 317. doi: 10.1016/j.nlm.2009.03.008

De Bellis, M. D., and Kuchibhatla, M. (2006). Cerebellar volumes in pediatric maltreatment-related posttraumatic stress disorder. Biol. Psychiatry 60, 697703. doi: 10.1016/j.biopsych.2006.04.035

De Chiara, V., Errico, F., Musella, A., Rossi, S., Mataluni, G., Sacchetti, L., et al. (2010). Voluntary exercise and sucrose consumption enhance cannabinoid CB1 receptor sensitivity in the striatum. Neuropsychopharmacology 35, 374-387. doi: $10.1038 / n p p .2009 .141$

Delgado, M. R. (2007). Reward-related responses in the human striatum. Ann. NY Acad. Sci. 1104, 70-88. doi: 10.1196/annals.1390.002

Delgado, M. R., Jou, R. L., LeDoux, J. E., and Phelps, E. A. (2009). Avoiding negative outcomes: tracking the mechanisms of avoidance learning in humans during fear conditioning. Front. Behav. Neurosci. 3:33. doi: 10.3389/neuro.08.033. 2009

DeLong, M. R. (1990). Primate models of movement disorders of basal ganglia origin. Trends Neurosci. 13, 281-285. doi: 10.1016/0166-2236(90)90110-v

De Luca, M. A., Solinas, M., Bimpisidis, Z., Goldberg, S. R., and Di Chiara, G. (2012). Cannabinoid facilitation of behavioral and biochemical hedonic taste responses. Neuropharmacology 63, 161-168. doi: 10.1016/j.neuropharm.2011. 10.018
De Vries, T. J., Shaham, Y., Homberg, J. R., Crombag, H., Schuurman, K., Dieben, J., et al. (2001). A cannabinoid mechanism in relapse to cocaine seeking. Nat. Med. 7, 1151-1154. doi: 10.1038/nm1001-1151

DeYoung, C. G., Hirsh, J. B., Shane, M. S., Papademetris, X., Rajeevan, N., and Gray, J. R. (2010). Testing predictions from personality neuroscience. Brain structure and the big five. Psychol. Sci. 21, 820-828. doi: 10.1177/09567976103 70159

Digman, J. M. (1990). Personality structure: emergence of the five-factor model. Annu. Rev. Psychol. 41, 417-440. doi: 10.1146/annurev.ps.41.020190.002221

Di Marzo, V., Bifulco, M., and De Petrocellis, L. (2004). The endocannabinoid system and its therapeutic exploitation. Nat. Rev. Drug Discov. 3, 771-784. doi: $10.1038 / \mathrm{nrd} 1495$

Di Marzo, V., and Matias, I. (2005). Endocannabinoid control of food intake and energy balance. Nat. Neurosci. 8, 585-589. doi: 10.1038/nn1457

Di Paola, M., Caltagirone, C., and Petrosini, L. (2013). Prolonged rock climbing activity induces structural changes in cerebellum and parietal lobe. Hum. Brain Mapp. 34, 2707-2714. doi: 10.1002/hbm.22095

Duarte, C., Alonso, R., Bichet, N., Cohen, C., Soubrié, P., and Thiébot, M. H. (2004). Blockade by the cannabinoid CB1 receptor antagonist, rimonabant (SR141716), of the potentiation by quinelorane of food-primed reinstatement of food-seeking behavior. Neuropsychopharmacology 29, 911-920. doi: 10.1038/sj. npp. 1300370

Duclot, F., and Kabbaj, M. (2013). Individual differences in novelty seeking predict subsequent vulnerability to social defeat through a differential epigenetic regulation of brain-derived neurotrophic factor expression. J. Neurosci. 33, 11048 11060. doi: 10.1523/JNEUROSCI.0199-13.2013

Dulawa, S. C., and Hen, R. (2005). Recent advances in animal models of chronic antidepressant effects: the novelty-induced hypophagia test. Neurosci. Biobehav. Rev. 29, 771-783. doi: 10.1016/j.neubiorev.2005.03.017

Durieux, P. F., Bearzatto, B., Guiducci, S., Buch, T., Waisman, A., Zoli, M., et al. (2009). D2R striatopallidal neurons inhibit both locomotor and drug reward processes. Nat. Neurosci. 12, 393-395. doi: 10.1038/nn.2286

Dymond, S., Schlund, M. W., Roche, B., Whelan, R., Richards, J., and Davies, C. (2011). Inferred threat and safety: symbolic generalization of human avoidance learning. Behav. Res. Ther. 49, 614-621. doi: 10.1016/j.brat.2011.06.007

Eisenberger, N. I., Lieberman, M. D., and Satpute, A. B. (2005). Personality from a controlled processing perspective: an fMRI study of neuroticism, extraversion and self-consciousness. Cogn. Affect. Behav. Neurosci. 5, 169-181. doi: 10. 3758/cabn.5.2.169

Elliot, A. J. (1999). Approach and avoidance motivation and achievement goals. Educ. Psychol. 34, 169-189. doi: 10.1207/s15326985ep3403_3

Elliot, A. J. (2005). “A conceptual history of the achievement goal construct," in Handbook of Competence and Motivation, eds A. Elliot and C. Dweck (New York: Guilford), 52-72.

Elliot, A. J. (2006). The hierarchical model of approach-avoidance motivation. Motiv. Emot. 30, 111-116. doi: 10.1007/s11031-006-9028-7

Elliot, A. J. (2008). “Approach and avoidance motivation," in Handbook of Approach and Avoidance Motivation, ed A. Elliot (New York: Taylor and Francis Group Psychology Press), 3-14.

Elliot, A. J., and Church, M. A. (1997). A hierarchical model of approach and avoidance achievement motivation. J. Pers. Soc. Psychol. 72, 218-232. doi: 10. 1037//0022-3514.72.1.218

Elliot, A. J., Gable, S. L., and Mapes, R. R. (2006). Approach and avoidance motivation in the social domain. Pers. Soc. Psychol. Bull. 32, 378-391. doi: 10. $1177 / 0146167205282153$

Elliot, A. J., and Thrash, T. M. (2002). Approach-avoidance motivation in personality: approach and avoidance temperaments and goals. J. Pers. Soc. Psychol. 82, 804-818. doi: 10.1037//0022-3514.82.5.804

Evans, S. M., Haney, M., and Foltin, R. W. (2002). The effects of smoked cocaine during the follicular and luteal phases of the menstrual cycle in women. Psychopharmacology (Berl) 159, 397-406. doi: 10.1007/s00213-001-0944-7

Everitt, B. J., and Wolf, M. E. (2002). Psychomotor stimulant addiction: a neural systems perspective. J. Neurosci. 22, 3312-3320. doi: 10.1385/1-59259-306-2:183 Eysenck, H. J. (1981). A Model for Personality. New York: Springer Verlag.

Fadda, P., Scherma, M., Spano, M. S., Salis, P., Melis, V., Fattore, L., et al. (2006). Cannabinoid self-administration increases dopamine release in the nucleus accumbens. Neuroreport 17, 1629-1632. doi: 10.1097/01.wnr.0000236853. $40221.8 \mathrm{e}$ 
Fairbanks, L. A. (2001). Individual differences in response to a stranger: social impulsivity as a dimension of temperament in vervet monkeys (Cercopithecus aethiops sabaeus). J. Comp. Psychol. 115, 22-28. doi: 10.1037//0735-7036. 115.1.22

Fattore, L., Spano, M. S., Cossu, G., Deiana, S., and Fratta, W. (2003). Cannabinoid mechanism in reinstatement of heroin-seeking after a long period of abstinence in rats. Eur. J. Neurosci. 17, 1723-1726. doi: 10.1046/j.1460-9568.2003. 02607.x

Feltenstein, M. W., and See, R. E. (2007). Plasma progesterone levels and cocaineseeking in freely cycling female rats across the estrous cycle. Drug Alcohol Depend. 89, 183-189. doi: 10.1016/j.drugalcdep.2006.12.017

Ferguson, S. M., Eskenazi, D., Ishikawa, M., Wanat, M. J., Phillips, P. E., Dong, Y., et al. (2011). Transient neuronal inhibition reveals opposing roles of indirect and direct pathways in sensitization. Nat. Neurosci. 14, 22-24. doi: 10.1038/nn. 2703

Fernández-Ruiz, J., Hernández, M., and Ramos, J. A. (2010). Cannabinoiddopamine interaction in the pathophysiology and treatment of CNS disorders. CNS Neurosci. Ther. 16, e72-e91. doi: 10.1111/j.1755-5949.2010.00144.x

Ferreira, T. L., Moreira, K. M., Ikeda, D. C., Bueno, O. F., and Oliveira, M. G. (2003). Effects of dorsal striatum lesions in tone fear conditioning and contextual fear conditioning. Brain Res. 987, 17-24. doi: 10.1016/s0006-8993(03)03217-7

Ferreira, T. L., Shammah-Lagnado, S. J., Bueno, O. F., Moreira, K. M., Fornari, R. V., and Oliveira, M. G. (2008). The indirect amygdala-dorsal striatum pathway mediates conditioned freezing: insights on emotional memory networks. Neuroscience 153, 84-94. doi: 10.1016/j.neuroscience.2008.02.013

File, S. E., and Seth, P. (2003). A review of 25 years of the social interaction test. Eur. J. Pharmacol. 463, 35-53. doi: 10.1016/s0014-2999(03)01273-1

Fiorillo, C. D. (2013). Two dimensions of value: dopamine neurons represent reward but not aversiveness. Science 341, 546-549. doi: 10.1126/science.1238699

Fitzgerald, P. B., Laird, A. R., Maller, J., and Daskalakis, Z. J. (2008). A meta-analytic study of changes in brain activation in depression. Hum. Brain Mapp. 29, 683695. doi: 10.1002/hbm.20426

Flagel, S. B., Akil, H., and Robinson, T. E. (2009). Individual differences in the attribution of incentive salience to reward-related cues: implications for addiction. Neuropharmacology 56, 139-148. doi: 10.1016/j.neuropharm.2008. 06.027

Flagel, S. B., Waselus, M., Clinton, S. M., Watson, S. J., and Akil, H. (2014). Antecedents and consequences of drug abuse in rats selectively bred for high and low response to novelty. Neuropharmacology 76, 425-436. doi: 10.1016/j. neuropharm.2013.04.033

Foti, F., Mandolesi, L., Cutuli, D., Laricchiuta, D., De Bartolo, P., Gelfo, F., et al. (2010). Cerebellar damage loosens the strategic use of the spatial structure of the search space. Cerebellum 9, 29-41. doi: 10.1007/s12311-009-0134-4

Fowler, C. J., and Jacobsson, S. O. (2002). Cellular transport of anandamide, 2-arachidonoylglycerol and palmitoylethanolamide-targets for drug development? Prostaglandins Leukot. Essent. Fatty Acids 66, 193-200. doi: 10.1054/plef. 2001.0357

Fowler, C. J., Rojo, M. L., and Rodriguez-Gaztelumendi, A. (2010). Modulation of the endocannabinoid system: neuroprotection or neurotoxicity? Exp. Neurol. 224, 37-47. doi: 10.1016/j.expneurol.2010.03.021

Fredrickson, B. L. (2001). The role of positive emotions in positive psychology. The broaden-and-build theory of positive emotions. Am. Psychol. 56, 218-226. doi: 10.1037/0003-066x.56.3.218

Fredrickson, B. L. (2004). The broaden-and-build theory of positive emotions. Philos. Trans. R. Soc. Lond. B Biol. Sci. 359, 1367-1378. doi: 10.1098/rstb.2004. 1512

Fresán, A., Apiquian, R., Nicolini, H., and Cervantes, J. J. (2007). Temperament and character in violent schizophrenic patients. Schizophr. Res. 94, 74-80. doi: 10. 1016/j.schres.2007.04.005

Fresán, A., Robles-García, R., López-Avila, A., and Cloninger, C. R. (2011). Personality differences according to age and sex in a Mexican sample using the temperament and character inventory-revised. Compr. Psychiatry 52, 774-779. doi: 10.1016/j.comppsych.2010.11.003

Freund, T. F., Katona, I., and Piomelli, D. (2003). Role of endogenous cannabinoids in synaptic signaling. Physiol. Rev. 83, 1017-1066.

Gable, S. L., Reis, H. T., and Elliot, A. J. (2003). Evidence for bivariate systems: an empirical test of appetition and aversion across domains. J. Res. Pers. 37, 349372. doi: 10.1016/s0092-6566(02)00580-9
Gardini, S., Cloninger, C. R., and Venneri, A. (2009). Individual differences in personality traits reflect structural variance in specific brain regions. Brain Res. Bull. 79, 265-270. doi: 10.1016/j.brainresbull.2009.03.005

Gerdeman, G. L., and Lovinger, D. M. (2003). Emerging roles for endocannabinoids in long-term synaptic plasticity. Br. J. Pharmacol. 140, 781-789. doi: 10. 1038/sj.bjp.0705466

Gerdeman, G. L., Partridge, J. G., Lupica, C. R., and Lovinger, D. M. (2003). It could be habit forming: drugs of abuse and striatal synaptic plasticity. Trends Neurosci. 26, 184-192. doi: 10.1016/s0166-2236(03)00065-1

Gerra, G., Zaimovic, A., Timpano, M., Zambelli, U., Delsignore, R., and Brambilla, F. (2000). Neuroendocrine correlates of temperamental traits in humans. Psychoneuroendocrinology 25, 479-496. doi: 10.1016/s0306-4530(00)00004-4

Gjedde, A., Kumakura, Y., Cumming, P., Linnet, J., and Møller, A. (2010). InvertedU-shaped correlation between dopamine receptor availability in striatum and sensation seeking. Proc. Natl. Acad. Sci. U S A 107, 3870-3875. doi: 10.1073/pnas. 0912319107

Good, R. L., and Radcliffe, R. A. (2011). Methamphetamine-induced locomotor changes are dependent on age, dose and genotype. Pharmacol. Biochem. Behav. 98, 101-111. doi: 10.1016/j.pbb.2010.12.004

Gray, J. A. (1987). The Psychology of Fear and Stress. 2nd Edn. New York: Cambridge University Press.

Gray, J. A., and McNaughton, N. (2000). The Neuropsychology of Anxiety: An Enquiry into the Functions of the Septo-Hippocampal System. Oxford: Oxford University Press.

Graybiel, A. M., Aosaki, T., Flaherty, A. W., and Kimura, M. (1994). The basal ganglia and adaptive motor control. Science 265, 1826-1831. doi: 10.1126/science. 8091209

Greenberg, R. (2003). "The role of neophobia and neophilia in the development of innovative behaviour of birds," in Animal Innovation, eds S. M. Reader and K. N. Laland (Oxford, England: Oxford University Press), 175-196.

Groppe, S. E., Gossen, A., Rademacher, L., Hahn, A., Westphal, L., Gründer, G., et al. (2013). Oxytocin influences processing of socially relevant cues in the ventral tegmental area of the human brain. Biol. Psychiatry 74, 172-179. doi: 10. 1016/j.biopsych.2012.12.023

Gunduz-Cinar, O., MacPherson, K. P., Cinar, R., Gamble-George, J., Sugden, K., Williams, B., et al. (2013). Convergent translational evidence of a role for anandamide in amygdala-mediated fear extinction, threat processing and stressreactivity. Mol. Psychiatry 18, 813-823. doi: 10.1038/mp.2012.72

Hampe, C. S., Petrosini, L., De Bartolo, P., Caporali, P., Cutuli, D., Laricchiuta, D., et al. (2013). Monoclonal antibodies to $65 \mathrm{kDa}$ glutamate decarboxylase induce epitope specific effects on motor and cognitive functions in rats. Orphanet $J$. Rare Dis. 8:82. doi: 10.1186/1750-1172-8-82

Häring, M., Kaiser, N., Monory, K., and Lutz, B. (2011). Circuit specific functions of cannabinoid CB1 receptor in the balance of investigatory drive and exploration. PLoS One 6:e26617. doi: 10.1371/journal.pone.0026617

Hariri, A. R. (2009). The neurobiology of individual differences in complex behavioral traits. Annu. Rev. Neurosci. 32, 225-247. doi: 10.1146/annurev.neuro. 051508.135335

Harkany, T., Keimpema, E., Barabás, K., and Mulder, J. (2008). Endocannabinoid functions controlling neuronal specification during brain development. Mol. Cell. Endocrinol. 286, S84-S90. doi: 10.1016/j.mce.2008.02.011

Heath, R. (1963). "Electrical self-stimulation of the brain in man," in 119th Annual Meeting of the American Psychiatric Association (St. Louis, MO: American Psychiatric Association).

Hefner, K., and Holmes, A. (2007). Ontogeny of fear-, anxiety- and depressionrelated behavior across adolescence in C57BL/6J mice. Behav. Brain Res. 176, 210-215. doi: 10.1016/j.bbr.2006.10.001

Heitland, I., Klumpers, F., Oosting, R. S., Evers, D. J., Leon Kenemans, J., and Baas, J. M. (2012). Failure to extinguish fear and genetic variability in the human cannabinoid receptor 1. Transl. Psychiatry 2:e162. doi: 10.1038/tp.2012.90

Helfinstein, S. M., Benson, B., Perez-Edgar, K., Bar-Haim, Y., Detloff, A., Pine, D. S., et al. (2011). Striatal responses to negative monetary outcomes differ between temperamentally inhibited and non-inhibited adolescents. Neuropsychologia 49, 479-485. doi: 10.1016/j.neuropsychologia.2010.12.015

Helm, K. A., Rada, P., and Hoebel, B. G. (2003). Cholecystokinin combined with serotonin in the hypothalamus limits accumbens dopamine release while increasing acetylcholine: a possible satiation mechanism. Brain Res. 963, 290297. doi: 10.1016/s0006-8993(02)04051-9 
Henderson, H. A., and Wachs, T. D. (2007). Temperament theory and the study of cognition emotion interactions across development. Dev. Rev. 27, 396-427. doi: 10.1016/j.dr.2007.06.004

Herkenham, M., Lynn, A. B., Little, M. D., Johnson, M. R., Melvin, L. S., de Costa, B. R., et al. (1990). Cannabinoid receptor localization in brain. Proc. Natl. Acad. Sci. U S A 87, 1932-1936. doi: 10.1073/pnas.87.5.1932

Hermans, E. J., Putman, P., Baas, J. M., Gecks, N. M., Kenemans, J. L., and van Honk, J. (2007). Exogenous testosterone attenuates the integrated central stress response in healthy young women. Psychoneuroendocrinology 32, 1052-1061. doi: 10.1016/j.psyneuen.2007.08.006

Hermans, E. J., Putman, P., Baas, J. M., Koppeschaar, H. P., and van Honk, J. (2006). A single administration of testosterone reduces fear-potentiated startle in humans. Biol. Psychiatry 59, 872-874. doi: 10.1016/j.biopsych.2005.11.015

Higgs, S., Williams, C. M., and Kirkham, T. C. (2003). Cannabinoid influences on palatability: microstructural analysis of sucrose drinking after delta(9)tetrahydrocannabinol, anandamide, 2-arachidonoyl glycerol and SR141716. Psychopharmacology (Berl) 165, 370-377.

Hikida, T., Kimura, K., Wada, N., Funabiki, K., and Nakanishi, S. (2010). Distinct roles of synaptic transmission in direct and indirect striatal pathways to reward and aversive behavior. Neuron 66, 896-907. doi: 10.1016/j.neuron.2010.05.011

Hoebel, B. G., Avena, N. M., and Rada, P. (2007). Accumbens dopamineacetylcholine balance in approach and avoidance. Curr. Opin. Pharmacol. 7, 617-627. doi: 10.1016/j.coph.2007.10.014

Hoshi, E., Tremblay, L., Féger, J., Carras, P. L., and Strick, P. L. (2005). The cerebellum communicates with the basal ganglia. Nat. Neurosci. 8, 1491-1493. doi: $10.1038 / \mathrm{nn} 1544$

Ikemoto, S., and Panksepp, J. (1999). The role of nucleus accumbens dopamine in motivated behavior: a unifying interpretation with special reference to reward-seeking. Brain Res. Brain Res. Rev. 31, 6-41. doi: 10.1016/s0165-0173(99) 00023-5

Ito, M. (2008). Control of mental activities by internal models in the cerebellum. Nat. Rev. Neurosci. 9, 304-313. doi: 10.1038/nrn2332

Jamshidi, N., and Taylor, D. A. (2001). Anandamide administration into the ventromedial hypothalamus stimulates appetite in rats. Br. J. Pharmacol. 134, 1151-1154. doi: 10.1038/sj.bjp.0704379

Jarrett, M. M., Limebeer, C. L., and Parker, L. A. (2005). Effect of Delta9tetrahydrocannabinol on sucrose palatability as measured by the taste reactivity test. Physiol. Behav. 86, 475-479. doi: 10.1016/j.physbeh.2005.08.033

Jones, A. C., and Gosling, S. D. (2008). "Individual differences in approach and avoidance motivation in animals," in Handbook of Approach and Avoidance Motivation, ed A. Elliot (New York: Taylor and Francis Group Psychology Press), $165-185$.

Kano, M., Ohno-Shosaku, T., Hashimotodani, Y., Uchigashima, M., and Watanabe, M. (2009). Endocannabinoid-mediated control of synaptic transmission. Physiol. Rev. 89, 309-380. doi: 10.1152/physrev.00019.2008

Kasch, K. L., Rottenberg, J., Arnow, B. A., and Gotlib, I. H. (2002). Behavioral activation and inhibition systems and the severity and course of depression. $J$. Abnorm. Psychol. 111, 589-597. doi: 10.1037//0021-843x.111.4.589

Kashdan, T. B., and Hofmann, S. G. (2008). The high-novelty-seeking, impulsive subtype of generalized social anxiety disorder. Depress. Anxiety 25, 535-541. doi: 10.1002/da.20382

Katona, I., Sperlágh, B., Sík, A., Käfalvi, A., Vizi, E. S., Mackie, K., et al. (1999). Presynaptically located CB1 cannabinoid receptors regulate GABA release from axon terminals of specific hippocampal interneurons. J. Neurosci. 19, 45444558.

Kawagoe, R., Takikawa, Y., and Hikosaka, O. (1998). Expectation of reward modulates cognitive signals in the basal ganglia. Nat. Neurosci. 1, 411-416. doi: 10. $1038 / 1625$

Kelley, A. E., Baldo, B. A., Pratt, W. E., and Will, M. J. (2005). Corticostriatalhypothalamic circuitry and food motivation: integration of energy, action and reward. Physiol. Behav. 86, 773-795. doi: 10.1016/j.physbeh.2005. 08.066

Kerstetter, K. A., Aguilar, V. R., Parrish, A. B., and Kippin, T. E. (2008). Protracted time-dependent increases in cocaine-seeking behavior during cocaine withdrawal in female relative to male rats. Psychopharmacology (Berl) 198, 6375. doi: 10.1007/s00213-008-1089-8

Kerstetter, K. A., Su, Z. I., Ettenberg, A., and Kippin, T. E. (2013). Sex and estrous cycle differences in cocaine-induced approach-avoidance conflict. Addict. Biol. 18, 222-229. doi: 10.1111/j.1369-1600.2010.00292.x
Kilpatrick, M. R., Rooney, M. B., Michael, D. J., and Wight-man, R. M. (2000). Extracellular dopamine dynamics in rat caudate-putamen during experimenterdelivered and intracranial self-stimulation. Neuroscience 96, 697-706. doi: 10 . 1016/s0306-4522(99)00578-3

Kim, M. S., Cho, S. S., Kang, K. W., Hwang, J. L., and Kwon, J. S. (2002). Electrophysiological correlates of personality dimensions measured by temperament and character inventory. Psychiatry Clin. Neurosci. 56, 631-635. doi: 10.1046/j. 1440-1819.2002.01067.x

Knutson, B., Momenan, R., Rawlings, R. R., Fong, G. W., and Hommer, D. (2001). Negative association of neuroticism with brain volume ratio in healthy humans. Biol. Psychiatry 50, 685-690. doi: 10.1016/s0006-3223(01)01220-3

Koob, G. F., and Volkow, N. D. (2010). Neurocircuitry of addiction. Neuropsychopharmacology 35, 217-238. doi: 10.1038/npp.2009.110

Koziol, L. F., Budding, D. E., and Chidekel, D. (2010). Adaptation, expertise and giftedness: towards an understanding of cortical, subcortical and cerebellar network contributions. Cerebellum 9, 499-529. doi: 10.1007/s12311-010-0192-7

Kravitz, A. V., and Kreitzer, A. C. (2012). Striatal mechanisms underlying movement, reinforcement and punishment. Physiology (Bethesda) 27, 167-177. doi: 10.1152/physiol.00004.2012

Kravitz, A. V., Tye, L. D., and Kreitzer, A. C. (2012). Distinct roles for direct and indirect pathway striatal neurons in reinforcement. Nat. Neurosci. 15, 816-818. doi: 10.1038/nn.3100

Krishnan, V., Han, M. H., Graham, D. L., Berton, O., Renthal, W., Russo, S. J., et al. (2007). Molecular adaptations underlying susceptibility and resistance to social defeat in brain reward regions. Cell 131, 391-404. doi: 10.1016/j.cell.2007.09.018

Kumari, V., ffytche, D. H., Williams, S. C., and Gray, J. A. (2004). Personality predicts brain responses to cognitive demands. J. Neurosci. 24, 10636-10641. doi: 10.1523/jneurosci.3206-04.2004

Kunisato, Y., Okamoto, Y., Okada, G., Aoyama, S., Nishiyama, Y., Onoda, K., et al. (2011). Personality traits and the amplitude of spontaneous low-frequency oscillations during resting state. Neurosci. Lett. 492, 109-113. doi: 10.1016/j. neulet.2011.01.067

LaBar, K. S., and Cabeza, R. (2006). Cognitive neuroscience of emotional memory. Nat. Rev. Neurosci. 7, 54-64. doi: 10.1038/nrn1825

Lafenêtre, P., Chaouloff, F., and Marsicano, G. (2009). Bidirectional regulation of novelty-induced behavioral inhibition by the endocannabinoid system. $\mathrm{Neu}$ ropharmacology 57, 715-721. doi: 10.1016/j.neuropharm.2009.07.014

Lang, P. J., and Bradley, M. M. (2008). "Appetitive and defensive motivation is the substrate of emotion," in Handbook of Approach and Avoidance Motivation, ed A. Elliot (New York: Taylor and Francis Group Psychology Press), 51-65.

Lang, P., Bradley, M., and Cuthbert, B. (1997). "Motivated attention: affect, activation and action," in Attention and Orienting: Sensory and Motivational Processes, eds P. Lang, R. Simmons and M. Balaban (Florida: Lawrence Erlbaum Associates), 87-135.

Laricchiuta, D., Centonze, D., and Petrosini, L. (2013). Effects of endocannabinoid and endovanilloid systems on aversive memory extinction. Behav. Brain Res. 256, 101-107. doi: 10.1016/j.bbr.2013.08.010

Laricchiuta, D., Musella, A., Rossi, S., and Centonze, D. (2014a). Behavioral and electrophysiological effects of endocannabinoid and dopaminergic systems on salient stimuli. Front. Behav. Neurosci. 8:183. doi: 10.3389/fnbeh.2014.00183

Laricchiuta, D., Petrosini, L., Picerni, E., Cutuli, D., Iorio, M., Chiapponi, C., et al. (2014b). The embodied emotion in cerebellum: a neuroimaging study of alexithymia. Brain Struct. Funct. doi: 10.1007/s00429-014-0790-0. [Epub ahead of print].

Laricchiuta, D., Petrosini, L., Piras, F., Cutuli, D., Macci, E., Picerni, E., et al. (2014c). Linking novelty seeking and harm avoidance personality traits to basal ganglia: volumetry and mean diffusivity. Brain Struct. Funct. 219, 793-803. doi: 10.1007/s00429-013-0535-5

Laricchiuta, D., Petrosini, L., Piras, F., Macci, E., Cutuli, D., Chiapponi, C., et al. (2014d). Linking novelty seeking and harm avoidance personality traits to cerebellar volumes. Hum. Brain Mapp. 35, 285-296. doi: 10.1002/hbm.22174

Laricchiuta, D., Rojo, M. L., Rodriguez-Gaztelumendi, A., Ferlazzo, F., Petrosini, L., and Fowler, C. J. (2012a). CB1 receptor autoradiographic characterization of the individual differences in approach and avoidance motivation. PLoS One 7:e42111. doi: 10.1371/journal.pone.0042111

Laricchiuta, D., Rossi, S., Musella, A., De Chiara, V., Cutuli, D., Centonze, D., et al. (2012b). Differences in spontaneously avoiding or approaching mice reflect differences in CB1-mediated signaling of dorsal striatal transmission. PLoS One 7:e33260. doi: 10.1371/journal.pone.0033260 
Le Bihan, D. (2007). The 'wet mind': water and functional neuroimaging. Phys. Med. Biol. 52, R57-R90. doi: 10.1088/0031-9155/52/7/r02

LeDoux, J. E. (2000). Emotion circuits in the brain. Annu. Rev. Neurosci. 23, 155184. doi: 10.1146/annurev.neuro.23.1.155

LeDoux, J. E. (2012). Rethinking the emotional brain. Neuron 73, 653-676. doi: 10. 1016/j.neuron.2012.02.004

Lewin, K. (1935). A Dynamic Theory of Personality. New York: McGraw-Hill.

Li, Y., Li, S., Wei, C., Wang, H., Sui, N., and Kirouac, G. J. (2010). Changes in emotional behavior produced by orexin microinjections in the paraventricular nucleus of the thalamus. Pharmacol. Biochem. Behav. 95, 121-128. doi: 10. 1016/j.pbb.2009.12.016

Lilly, J. C. (1960). The psychophysiological basis for two kinds of instincts. Implications for psychoanalytic theory. J. Am. Psychoanal. Assoc. 8, 659-670. doi: 10. $1177 / 000306516000800402$

Limson, R., Goldman, D., Roy, A., Lamparski, D., Ravitz, B., Adinoff, B., et al. (1991). Personality and cerebrospinal fluid monoamine metabolites in alcoholics and controls. Arch. Gen. Psychiatry 48, 437-441. doi: 10.1001/archpsyc. 1991.01810290049010

Linfoot, I., Gray, M., Bingham, B., Williamson, M., Pinel, J. P., and Viau, V. (2009). Naturally occurring variations in defensive burying behavior are associated with differences in vasopressin, oxytocin and androgen receptors in the male rat. Prog. Neuropsychopharmacol. Biol. Psychiatry 33, 1129-1140. doi: 10.1016/j.pnpbp. 2009.06.008

Lobo, M. K., Covington, H. E., Chaudhury, D. 3rd, Friedman, A. K., Sun, H., Damez-Werno, D., et al. (2010). Cell type-specific loss of BDNF signaling mimics optogenetic control of cocaine reward. Science 330, 385-390. doi: 10. $1126 /$ science. 1188472

Loftus, S. T., Garno, J. L., Jaeger, J., and Malhotra, A. K. (2008). Temperament and character dimensions in bipolar I disorder: a comparison to healthy controls. $J$. Psychiatr. Res. 42, 1131-1136. doi: 10.1016/j.jpsychires.2007.11.005

Lombardo, M. V., Ashwin, E., Auyeung, B., Chakrabarti, B., Lai, M. C., Taylor, K., et al. (2012). Fetal programming effects of testosterone on the reward system and behavioral approach tendencies in humans. Biol. Psychiatry 72, 839-847. doi: 10.1016/j.biopsych.2012.05.027

Lovibond, P. F., Chen, S. X., Mitchell, C. J., and Weidemann, G. (2013). Competition between an avoidance response and a safety signal: evidence for a single learning system. Biol. Psychol. 92, 9-16. doi: 10.1016/j.biopsycho.2011.09.007

Lovibond, P. F., Saunders, J. C., Weidemann, G., and Mitchell, C. J. (2008). Evidence for expectancy as a mediator of avoidance and anxiety in a laboratory model of human avoidance learning. Q. J. Exp. Psychol. (Hove) 61, 1199-1216. doi: 10. 1080/17470210701503229

Lovinger, D. M. (2010). Neurotransmitter roles in synaptic modulation, plasticity and learning in the dorsal striatum. Neuropharmacology 58, 951-961. doi: 10. 1016/j.neuropharm.2010.01.008

Lupica, C. R., and Riegel, A. C. (2005). Endocannabinoid release from midbrain dopamine neurons: a potential substrate for cannabinoid receptor antagonist treatment of addiction. Neuropharmacology 48, 1105-1116. doi: 10.1016/j. neuropharm.2005.03.016

Lutz, B. (2007). The endocannabinoid system and extinction learning. Mol. Neurobiol. 36, 92-101. doi: 10.1007/s12035-007-8004-x

Lutz, B. (2009). Endocannabinoid signals in the control of emotion. Curr. Opin. Pharmacol. 9, 46-52. doi: 10.1016/j.coph.2008.12.001

Lynch, W. J., Roth, M. E., and Carroll, M. E. (2002). Biological basis of sex differences in drug abuse: preclinical and clinical studies. Psychopharmacology 164, 121-137. doi: 10.1007/s00213-002-1183-2

Maccarrone, M., Gubellini, P., Bari, M., Picconi, B., Battista, N., Centonze, D., et al. (2003). Levodopa treatment reverses endocannabinoid system abnormalities in experimental parkinsonism. J. Neurochem. 85, 1018-1025. doi: 10.1046/j.14714159.2003.01759.x

Maldonado, R., and Rodríguez de Fonseca, F. (2002). Cannabinoid addiction: behavioral models and neural correlates. J. Neurosci. 22, 3326-3331.

Maldonado, R., Valverde, O., and Berrendero, F. (2006). Involvement of the endocannabinoid system in drug addiction. Trends Neurosci. 29, 225-232. doi: 10. 1016/j.tins.2006.01.008

Marsicano, G., and Lutz, B. (1999). Expression of the cannabinoid receptor CB1 in distinct neuronal subpopulations in the adult mouse forebrain. Eur. J. Neurosci. 11, 4213-4225. doi: 10.1046/j.1460-9568.1999.00847.x

Marsicano, G., and Lutz, B. (2006). Neuromodulatory functions of the endocannabinoid system. J. Endocrinol. Invest. 29, 27-46.
Martin, L. E., and Potts, G. F. (2004). Reward sensitivity in impulsivity. Neuroreport 15, 1519-1522. doi: 10.1097/01.wnr.0000132920.12990.b9

Martinotti, G., Andreoli, S., Giametta, E., Poli, V., Bria, P., and Janiri, L. (2006). The dimensional assessment of personality in pathologic and social gamblers: the role of novelty seeking and self-transcendence. Compr. Psychiatry 47, 350356. doi: 10.1016/j.comppsych.2005.12.005

Matias, I., and Di Marzo, V. (2007). Endocannabinoids and the control of energy balance. Trends Endocrinol. Metab. 18, 27-37. doi: 10.1016/j.tem.2006.11.006

Matsumoto, M., and Hikosaka, O. (2009). Two types of dopamine neuron distinctly convey positive and negative motivational signals. Nature 459, 837-841. doi: 10 . 1038/nature08028

McClelland, D., Atkinson, J., Clark, R., and Lowell, E. (1953). The Achievement Motive. New York: Irvington Publishers.

McDonald, J., Schleifer, L., Richards, J. B., and de Wit, H. (2003). Effects of THC on behavioral measures of impulsivity in humans. Neuropsychopharmacology 28 , 1356-1365. doi: 10.1038/sj.npp.1300176

McGaugh, J. L. (2004). The amygdala modulates the consolidation of memories of emotionally arousing experiences. Annu. Rev. Neurosci. 27, 1-28. doi: 10. 1146/annurev.neuro.27.070203.144157

McNab, F., and Klingberg, T. (2008). Prefrontal cortex and basal ganglia control access to working memory. Nat. Neurosci. 11, 103-107. doi: 10.1038/ nn2024

McNaughton, N., and Corr, P. J. (2004). A two-dimensional neuropsychology of defense: fear/anxiety and defensive distance. Neurosci. Biobehav. Rev. 28, 285305. doi: 10.1016/j.neubiorev.2004.03.005

McNaughton, N., and Corr, P. J. (2014). Approach, avoidance and their conflict: the problem of anchoring. Front. Syst. Neurosci. 8:124. doi: 10.3389/fnsys.2014. 00124

McNaughton, N., and Gray, J. A. (2000). Anxiolytic action on the behavioural inhibition system implies multiple types of arousal contribute to anxiety. $J$. Affect. Disord. 61, 161-176. doi: 10.1016/s0165-0327(00)00344-x

Meyer, B., Johnson, S. L., and Carver, C. S. (1999). Exploring behavioral activation and inhibition sensitivities among college students at risk for bipolar spectrum symptomatology. J. Psychopathol. Behav. Assess. 21, 275-292. doi: 10. 1023/A:1022119414440

Miguelez, M., Bielajew, C. H., Diotte, M., and Shiao, R. (2001). Dynamic changes in cytochrome oxidase activity in the amygdala following lesions of rewarding sites in the lateral hypothalamus. Behav. Brain Res. 119, 103-110. doi: 10.1016/ s0166-4328(00)00340-5

Miller, N. (1944). "Experimental studies of conflict," in Personality and The Behavioral Disorders, ed J. McV. Hunt (New York: Ronald Press), 431-465.

Mitchell, J. T., and Nelson-Gray, R. O. (2006). Attention-deficit/hyperactivity disorder symptoms in adults: relationship to Gray's behavioral approach system. Pers. Individ. Differ. 40, 749-760. doi: 10.1016/j.paid.2005.08.011

Mogi, K., Ooyama, R., Nagasawa, M., and Kikusui, T. (2014). Effects of neonatal oxytocin manipulation on development of social behaviors in mice. Physiol. Behav. 133, 68-75. doi: 10.1016/j.physbeh.2014.05.010

Molet, M., Leconte, C., and Rosas, J. M. (2006). Acquisition, extinction and temporal discrimination in human conditioned avoidance. Behav. Processes 73 , 199-208. doi: 10.1016/j.beproc.2006.05.009

Montag, C., Markett, S., Basten, U., Stelzel, C., Fiebach, C., Canli, T., et al. (2010). Epistasis of the DRD2/ANKK1 Taq Ia and the BDNF Val66Met polymorphism impacts novelty seeking and harm avoidance. Neuropsychopharmacology 35, 1860-1867. doi: 10.1038/npp.2010.55

Moreira, F. A., Kaiser, N., Monory, K., and Lutz, B. (2008). Reduced anxietylike behaviour induced by genetic and pharmacological inhibition of the endocannabinoid-degrading enzyme fatty acid amide hydrolase (FAAH) is mediated by CB1 receptors. Neuropharmacology 54, 141-150. doi: 10.1016/j. neuropharm.2007.07.005

Moreno, M., Cardona, D., Gómez, M. J., Sánchez-Santed, F., Tobeña, A., FernándezTeruel, A., et al. (2010). Impulsivity characterization in the Roman high- and low-avoidance rat strains: behavioral and neurochemical differences. Neuropsychopharmacology 35, 1198-1208. doi: 10.1038/npp.2009.224

Moresco, F. M., Dieci, M., Vita, A., Messa, C., Gobbo, C., Galli, L., et al. (2002). In vivo serotonin $5 \mathrm{HT}(2 \mathrm{~A})$ receptor binding and personality traits in healthy subjects: a positron emission tomography study. Neuroimage 17, 1470-1478. doi: 10.1006/nimg.2002.1239

Morrow, J. D., Maren, S., and Robinson, T. E. (2011). Individual variation in the propensity to attribute incentive salience to an appetitive cue predicts the 
propensity to attribute motivational salience to an aversive cue. Behav. Brain Res. 220, 238-243. doi: 10.1016/j.bbr.2011.02.013

Mulder, J., Aguado, T., Keimpema, E., Barabás, K., Ballester Rosado, C. J., Nguyen, L., et al. (2008). Endocannabinoid signaling controls pyramidal cell specification and long-range axon patterning. Proc. Natl. Acad. Sci. U S A 105, 8760-8765. doi: $10.1073 /$ pnas. 0803545105

Muris, P., Merckelbach, H., Schmidt, H., Gadet, B. B., and Bogie, N. (2001). Anxiety and depression as correlates of self-reported behavioural inhibition in normal adolescents. Behav. Res. Ther. 39, 1051-1061. doi: 10.1016/s00057967(00)00081-4

Nader, J., Rapino, C., Gennequin, B., Chavant, F., Francheteau, M., Makriyannis, A., et al. (2014). Prior stimulation of the endocannabinoid system prevents methamphetamine-induced dopaminergic neurotoxicity in the striatum through activation of $\mathrm{CB}(2)$ receptors. Neuropharmacology 87, 214-221. doi: 10. 1016/j.neuropharm.2014.03.014

Naidu, P. S., Varvel, S. A., Ahn, K., Cravatt, B. F., Martin, B. R., and Lichtman, A. H. (2007). Evaluation of fatty acid amide hydrolase inhibition in murine models of emotionality. Psychopharmacology (Berl) 192, 61-70. doi: 10.1007/s00213-006$0689-4$

Nasser, H. M., and McNally, G. P. (2012). Appetitive-aversive interactions in Pavlovian fear conditioning. Behav. Neurosci. 126, 404-422. doi: 10.1037/a0028341

Nazzaro, C., Greco, B., Cerovic, M., Baxter, P., Rubino, T., Trusel, M., et al. (2012). SK channel modulation rescues striatal plasticity and control over habit in cannabinoid tolerance. Nat. Neurosci. 15, 284-293. doi: 10.1038/nn.3022

Nelson, E. E., and Panksepp, J. (1998). Brain substrates of infant-mother attachment: contributions of opioids, oxytocin and norepinephrine. Neurosci. Biobehav. Rev. 22, 437-452. doi: 10.1016/s0149-7634(97)00052-3

O’Doherty, J. P., Deichmann, R., Critchley, H. D., and Dolan, R. J. (2002). Neural responses during anticipation of a primary taste reward. Neuron 33, 815-826. doi: 10.1016/s0896-6273(02)00603-7

O'Doherty, J., Rolls, E. T., Francis, S., Bowtell, R., McGlone, F., Kobal, G., et al. (2000). Sensory-specific satiety-related olfactory activation of the human orbitofrontal cortex. Neuroreport 11, 893-897. doi: 10.1097/00001756200003200-00046

O'Gorman, R. L., Kumari, V., Williams, S. C., Zelaya, F. O., Connor, S. E., Alsop, D. C., et al. (2006). Personality factors correlate with regional cerebral perfusion. Neuroimage 31, 489-495. doi: 10.1016/j.neuroimage.2005.12.048

Ohno-Shosaku, T., and Kano, M. (2014). Endocannabinoid-mediated retrograde modulation of synaptic transmission. Curr. Opin. Neurobiol. 29C, 1-8. doi: 10. 1016/j.conb.2014.03.017

Oliveri, M., Torriero, S., Koch, G., Salerno, S., Petrosini, L., and Caltagirone, C. (2007). The role of transcranial magnetic stimulation in the study of cerebellar cognitive function. Cerebellum 6, 95-101. doi: 10.1080/14734220701213421

Ono, Y., Ando, J., Onoda, N., Yoshimura, K., Momose, T., Hirano, M., et al. (2002). Dimensions of temperament as vulnerability factors in depression. Mol. Psychiatry 7, 948-953. doi: 10.1038/sj.mp.4001122

Pagotto, U., Marsicano, G., Cota, D., Lutz, B., and Pasquali, R. (2006). The emerging role of the endocannabinoid system in endocrine regulation and energy balance. Endocr. Rev. 27, 73-100. doi: 10.1210/er.2005-0009

Palmiter, R. D. (2008). Dopamine signaling in the dorsal striatum is essential for motivated behaviors: lessons from dopamine-deficient mice. Ann. N Y Acad. Sci. 1129, 35-46. doi: 10.1196/annals.1417.003

Pangelinan, M. M., Zhang, G., VanMeter, J. W., Clark, J. E., Hatfield, B. D., and Haufler, A. J. (2011). Beyond age and gender: relationships between cortical and subcortical brain volume and cognitive-motor abilities in schoolage children. Neuroimage 54, 3093-3100. doi: 10.1016/j.neuroimage.2010. 11.021

Pape, H. C., and Pare, D. (2010). Plastic synaptic networks of the amygdala for the acquisition, expression and extinction of conditioned fear. Physiol. Rev. 90, 419463. doi: 10.1152/physrev.00037.2009

Patel, S., and Hillard, C. J. (2008). Adaptations in endocannabinoid signaling in response to repeated homotypic stress: a novel mechanism for stress habituation. Eur. J. Neurosci. 27, 2821-2829. doi: 10.1111/j.1460-9568.2008. 06266.x

Pattij, T., Janssen, M. C., Schepers, I., González-Cuevas, G., de Vries, T. J., and Schoffelmeer, A. N. (2007). Effects of the cannabinoid CB1 receptor antagonist rimonabant on distinct measures of impulsive behavior in rats. Psychopharmacology (Berl) 193, 85-96. doi: 10.1007/s00213-007-0773-4
Pezze, M. A., and Feldon, J. (2004). Mesolimbic dopaminergic pathways in fear conditioning. Prog. Neurobiol. 74, 301-320. doi: 10.1016/j.pneurobio.2004. 09.004

Phillips, A. G., Carter, D. A., and Fibiger, H. C. (1976). Dopaminergic substrates of intracranial self-stimulation in the caudate-putamen. Brain Res. 104, 221-232. doi: 10.1016/0006-8993(76)90615-6

Phillips, A. G., Mora, F., and Rolls, E. T. (1979). Intracranial self-stimulation in orbitofrontal cortex and caudate nucleus of rhesus monkey: effects of apomorphine, pimozide and spiroperidol. Psychopharmacology (Berl) 62, 79-82. doi: 10. 1007/bf00426039

Picerni, E., Petrosini, L., Piras, F., Laricchiuta, D., Cutuli, D., Chiapponi, C., et al. (2013). New evidence for the cerebellar involvement in personality traits. Front. Behav. Neurosci. 7:133. doi: 10.3389/fnbeh.2013.00133

Pickering, A. D., and Gray, J. A. (2001). "Dopamine, appetitive reinforcement and the neuropsychology of human learning: an individual differences approach," in Advances in Individual Differences Research, ed A. Angleitner (Lengerich, Germany: PABST Science Publishers), 113-149.

Pietrzak, R. H., Huang, Y., Corsi-Travali, S., Zheng, M. Q., Lin, S. F., Henry, S., et al. (2014). Cannabinoid type 1 receptor availability in the amygdala mediates threat processing in trauma survivors. Neuropsychopharmacology 39, 2519-2528. doi: 10.1038/npp.2014.110

Pillay, S. S., Yurgelun-Todd, D. A., Bonello, C. M., Lafer, B., Fava, M., and Renshaw, P. F. (1997). A quantitative magnetic resonance imaging study of cerebral and cerebellar gray matter volume in primary unipolar major depression: relationship to treatment response and clinical severity. Biol. Psychiatry 42, 7984. doi: 10.1016/s0006-3223(96)00335-6

Piomelli, D. (2003). The molecular logic of endocannabinoid signalling. Nat. Rev. Neurosci. 4, 873-884. doi: 10.1038/nrn1247

Piomelli, D. (2014). More surprises lying ahead. The endocannabinoids keep us guessing. Neuropharmacology 76, 228-234. doi: 10.1016/j.neuropharm.2013.07. 026

Piras, F., Caltagirone, C., and Spalletta, G. (2010). Working memory performance and thalamus microstructure in healthy subjects. Neuroscience 171, 496-505. doi: 10.1016/j.neuroscience.2010.09.006

Piras, F., Cherubini, A., Caltagirone, C., and Spalletta, G. (2011). Education mediates microstructural changes in bilateral hippocampus. Hum. Brain Mapp. 32, 282-289. doi: 10.1002/hbm.21018

Plotnik, R., Mir, D., and Delgado, J. M. R. (1972). Map of reinforcing sites in the rhesus monkey brain. Int. J. Psychobiol. 2, 1-21.

Quilty, L. C., and Oakman, J. M. (2004). The assessment of behavioral activation. The relationship between positive emotionality and the behavioral activation system. Eur. J. Pers. 18, 557-571. doi: 10.1002/per.530

Restuccia, D., Della Marca, G., Valeriani, M., Leggio, M. G., and Molinari, M. (2007). Cerebellar damage impairs detection of somatosensory input changes. A somatosensory mismatch-negativity study. Brain 130, 276-287. doi: 10. 1093/brain/awl236

Rivera, P., Miguéns, M., Coria, S. M., Rubio, L., Higuera-Matas, A., BermúdezSilva, F. J., et al. (2013). Cocaine self-administration differentially modulates the expression of endogenous cannabinoid system-related proteins in the hippocampus of Lewis vs. Fischer 344 rats. Int. J. Neuropsychopharmacol. 16, 12771293. doi: $10.1017 / \mathrm{s} 1461145712001186$

Robbins, T. W., and Everitt, B. J. (1996). Neurobehavioural mechanisms of reward and motivation. Curr. Opin. Neurobiol. 6, 228-236. doi: 10.1016/s09594388(96) $80077-8$

Roberts, B. W., Caspi, A., and Moffitt, T. E. (2001). The kids are alright: growth and stability in personality development from adolescence to adulthood. J. Pers. Soc. Psychol. 81, 670-683. doi: 10.1037//0022-3514.81.4.670

Robinson, T. E., and Flagel, S. B. (2009). Dissociating the predictive and incentive motivational properties of reward-related cues through the study of individual differences. Biol. Psychiatry 65, 869-873. doi: 10.1016/j.biopsych.2008. 09.006

Robson, P. J., Guy, G. W., and Di Marzo, V. (2014). Cannabinoids and schizophrenia: therapeutic prospects. Curr. Pharm. Des. 20, 2194-2204. doi: 10. 2174/13816128113199990427

Roitman, M. F., Wheeler, R. A., and Carelli, R. M. (2005). Nucleus accumbens neurons are innately tuned for rewarding and aversive taste stimuli, encode their predictors and are linked to motor output. Neuron 45, 587-597. doi: 10.1016/j. neuron.2004.12.055 
Rossi, S., De Chiara, V., Musella, A., Kusayanagi, H., Mataluni, G., Bernardi, G., et al. (2008). Chronic psychoemotional stress impairs cannabinoid-receptormediated control of GABA transmission in the striatum. J. Neurosci. 28, 72847292. doi: 10.1523/JNEUROSCI.5346-07.2008

Rothbart, M. K., and Bates, J. E. (1998). “Temperament,” in Handbook of Child Psychology, ed N. Eisenberg (New York: Wiley Press), 105-188.

Rutter, M., Caspi, A., and Moffitt, T. E. (2003). Using sex differences in psychopathology to study causal mechanisms: unifying issues and research strategies. J. Child Psychol. Psychiatry 44, 1092-1115. doi: 10.1111/1469-7610. 00194

Saunders, B. T., and Robinson, T. E. (2010). A cocaine cue acts as an incentive stimulus in some but not others: implications for addiction. Biol. Psychiatry 67, 730-736. doi: 10.1016/j.biopsych.2009.11.015

Schlund, M. W., and Cataldo, M. F. (2010). Amygdala involvement in human avoidance, escape and approach behavior. Neuroimage 53, 769-776. doi: 10 . 1016/j.neuroimage.2010.06.058

Schlund, M. W., Siegle, G. J., Ladouceur, C. D., Silk, J. S., Cataldo, M. F., Forbes, E. E., et al. (2010). Nothing to fear? Neural systems supporting avoidance behavior in healthy youths. Neuroimage 52, 710-719. doi: 10.1016/j.neuroimage. 2010.04.244

Schmahmann, J. D. (2004). Disorders of the cerebellum: ataxia, dysmetria of thought and the cerebellar cognitive affective syndrome. J. Neuropsychiatry Clin. Neurosci. 16, 367-378. doi: 10.1176/appi.neuropsych.16.3.367

Schmahmann, J. D., and Sherman, J. C. (1998). The cerebellar cognitive affective syndrome. Brain 121, 561-579. doi: 10.1093/brain/121.4.561

Schmahmann, J. D., Weilburg, J. B., and Sherman, J. C. (2007). The neuropsychiatry of the cerebellum - insights from the clinic. Cerebellum 6, 254-267. doi: 10. 1080/14734220701490995

Schneirla, T. C. (1965). Aspects of stimulation and organization in approach/withdrawal processes underlying vertebrate behavioral development. Adv. Study Behav. 1, 1-74. doi: 10.1016/s0065-3454(08)60055-8

Schultz, W., Tremblay, L., and Hollerman, J. R. (2000). Reward processing in primate orbitofrontal cortex and basal ganglia. Cereb. Cortex 10, 272-284. doi: $10.1093 /$ cercor/10.3.272

Schultz, W., Tremblay, L., and Hollerman, J. R. (2003). Changes in behavior-related neuronal activity in the striatum during learning. Trends Neurosci. 26, 321-328. doi: 10.1016/s0166-2236(03)00122-x

Schutter, D. J., Hofman, D., Hoppenbrouwers, S. S., and Kenemans, J. L. (2011). Corticospinal state variability and hemispheric asymmetries in motivational tendencies. Biol. Psychol. 87, 450-452. doi: 10.1016/j.biopsycho.2011. 04.001

Schutter, D. J., Koolschijn, P. C., Peper, J. S., and Crone, E. A. (2012). The cerebellum link to neuroticism: a volumetric MRI association study in healthy volunteers. PLoS One 7:e37252. doi: 10.1371/journal.pone.0037252

Schutter, D. J., and van Honk, J. (2009). The cerebellum in emotion regulation: a repetitive transcranial magnetic stimulation study. Cerebellum 8, 28-34. doi: 10. 1007/s12311-008-0056-6

Schwartz, C. E., Wright, C. I., Shin, L. M., Kagan, J., and Rauch, S. L. (2003). Inhibited and uninhibited infants "grown up": adult amygdalar response to novelty. Science 300, 1952-1953. doi: 10.1126/science.1083703

Seidler, R. D. (2010). Neural correlates of motor learning, transfer of learning and learning to learn. Exerc. Sport Sci. Rev. 38, 3-9. doi: 10.1097/jes. 0b013e3181c5cce7

Sheynin, J., Beck, K. D., Pang, K. C., Servatius, R. J., Shikari, S., Ostovich, J., et al. (2014a). Behaviourally inhibited temperament and female sex, two vulnerability factors for anxiety disorders, facilitate conditioned avoidance (also) in humans. Behav. Processes 103, 228-235. doi: 10.1016/j.beproc.2014. 01.003

Sheynin, J., Beck, K. D., Servatius, R. J., and Myers, C. E. (2014b). Acquisition and extinction of human avoidance behavior: attenuating effect of safety signals and associations with anxiety vulnerabilities. Front. Behav. Neurosci. 8:323. doi: 10. 3389/fnbeh.2014.00323

Simon, J. J., Walther, S., Fiebach, C. J., Friederich, H. C., Stippich, C., Weisbrod, M., et al. (2010). Neural reward processing is modulated by approach- and avoidance-related personality traits. Neuroimage 49, 1868-1874. doi: 10.1016/j. neuroimage.2009.09.016

Solinas, M., Justinova, Z., Goldberg, S. R., and Tanda, G. (2006). Anandamide administration alone and after inhibition of fatty acid amide hydrolase (FAAH) increases dopamine levels in the nucleus accumbens shell in rats. J. Neurochem. 98, 408-419. doi: 10.1111/j.1471-4159.2006.03880.x

Spear, L. P. (2002). The adolescent brain and the college drinker: biological basis of propensity to use and misuse alcohol. J. Stud. Alcohol Suppl. 14, 71-81.

Staples, L. G., and Cornish, J. L. (2014). The orexin-1 receptor antagonist SB334867 attenuates anxiety in rats exposed to cat odor but not the elevated plus maze: an investigation of Trial 1 and Trial 2 effects. Horm. Behav. 65, 294-300. doi: 10.1016/j.yhbeh.2013.12.014

Stoodley, C. J., and Schmahmann, J. D. (2010). Evidence for topographic organization in the cerebellum of motor control versus cognitive and affective processing. Cortex 46, 831-844. doi: 10.1016/j.cortex.2009.11.008

Stoodley, C. J., Valera, E. M., and Schmahmann, J. D. (2012). Functional topography of the cerebellum for motor and cognitive tasks: an fMRI study. Neuroimage 59, 1560-1570. doi: 10.1016/j.neuroimage.2011.08.065

Sugiura, M., Kawashima, R., Nakagawa, M., Okada, K., Sato, T., Goto, R., et al. (2000). Correlation between human personality and neural activity in cerebral cortex. Neuroimage 11, 541-546. doi: 10.1006/nimg.2000.0564

Sullivan, R. M., Toufexis, D. J., and Wilson, D. A. (2008). "Development of olfactory modulated approach and avoidance motivated behaviors," in Handbook of Approach and Avoidance Motivation, ed A. Elliot (New York: Taylor and Francis Group Psychology Press), 127-147.

Taylor, J. E., and Sullman, M. J. (2009). What does the Driving and Riding Avoidance Scale (DRAS) measure? J. Anxiety Disord. 23, 504-510. doi: 10.1016/j. janxdis.2008.10.006

Tellegen, A. (1985). "Structures of mood and personality and their relevance to assessing anxiety, with an emphasis on self-report," in Anxiety and The Anxiety Disorders, eds H. A. Tuma and J. Maser (NJ: Erlbaum), 681-706.

Timmann, D., and Daum, I. (2007). Cerebellar contributions to cognitive functions: a progress report after two decades of research. Cerebellum 6, 159-162. doi: 10.1080/14734220701496448

Tobler, P. N., O’Doherty, J. P., Dolan, R. J., and Schultz, W. (2007). Reward value coding distinct from risk attitude-related uncertainty coding in human reward systems. J. Neurophysiol. 97, 1621-1632. doi: 10.1152/jn.00745. 2006

Tops, M., Boksem, M. A., Luu, P., and Tucker, D. M. (2010). Brain substrates of behavioral programs associated with self-regulation. Front. Psychol. 1:152. doi: 10.3389/fpsyg.2010.00152

Torriero, S., Oliveri, M., Koch, G., Lo Gerfo, E., Salerno, S., Petrosini, L., et al. (2007). Cortical networks of procedural learning: evidence from cerebellar damage. Neuropsychologia 45, 1208-1214. doi: 10.1016/j.neuropsychologia.2006. 10.007

Trezza, V., Cuomo, V., and Vanderschuren, L. J. (2008). Cannabis and the developing brain: insights from behavior. Eur. J. Pharmacol. 585, 441-452. doi: 10. 1016/j.ejphar.2008.01.058

Tsai, H. C., Zhang, F., Adamantidis, A., Stuber, G. D., Bonci, A., de Lecea, L., et al. (2009). Phasic firing in dopaminergic neurons is sufficient for behavioral conditioning. Science 324, 1080-1084. doi: 10.1126/science.116 8878

van Honk, J., Schutter, D. J., Hermans, E. J., Putman, P., Tuiten, A., and Koppeschaar, H. (2004). Testosterone shifts the balance between sensitivity for punishment and reward in healthy young women. Psychoneuroendocrinology 29, 937-943. doi: 10.1016/j.psyneuen.2003.08.007

Van Laere, K., Goffin, K., Bormans, G., Casteels, C., Mortelmans, L., de Hoon, J., et al. (2009). Relationship of type 1 cannabinoid receptor availability in the human brain to novelty-seeking temperament. Arch. Gen. Psychiatry 66, 196204. doi: 10.1001/archgenpsychiatry.2008.530

van Schouwenburg, M. R., den Ouden, H. E., and Cools, R. (2010). The human basal ganglia modulate frontal-posterior connectivity during attention shifting. J. Neurosci. 30, 9910-9918. doi: 10.1523/jneurosci.1111-10. 2010

Verheij, M. M., and Cools, A. R. (2008). Twenty years of dopamine research: individual differences in the response of accumbal dopamine to environmental and pharmacological challenges. Eur. J. Pharmacol. 585, 228-244. doi: 10.1016/j. ejphar.2008.02.084

Villablanca, J. R., Marcus, R. J., and Olmstead, C. E. (1976). Effects of caudate nuclei or frontal cortical ablations in cats. I. Neurology and gross behavior. Exp. Neurol. 52, 389-420. doi: 10.1016/0014-4886(76)90213-2 
Wei, L., Duan, X., Yang, Y., Liao, W., Gao, Q., Ding, J. R., et al. (2011). The synchronization of spontaneous BOLD activity predicts extraversion and neuroticism. Brain Res. 1419, 68-75. doi: 10.1016/j.brainres.2011.08.060

Weierich, M. R., Wright, C. I., Negreira, A., Dickerson, B. C., and Barrett, L. F. (2010). Novelty as a dimension in the affective brain. Neuroimage 49, 2871-2878. doi: 10.1016/j.neuroimage.2009.09.047

Westlye, L. T., Bjørnebekk, A., Grydeland, H., Fjell, A. M., and Walhovd, K. B. (2011). Linking an anxiety-related personality trait to brain white matter microstructure: diffusion tensor imaging and harm avoidance. Arch. Gen. Psychiatry 68, 369-377. doi: 10.1001/archgenpsychiatry. 2011.24

Wheeler, R. E., Davidson, R. J., and Tomarken, A. J. (1993). Frontal brain asymmetry and emotional reactivity: a biological substrate of affective style. Psychophysiology 30, 82-89. doi: 10.1111/j.1469-8986.1993.tb03207.x

Wise, R. A. (2004). Rewards wanted: molecular mechanisms of motivation. Discov. Med. 4, 180-186.

Wise, R. A. (2006). Role of brain dopamine in food reward and reinforcement. Philos. Trans. R. Soc. Lond. B Biol. Sci. 361, 1149-1158. doi: 10.1098/rstb.2006. 1854

Witkin, J. M., Tzavara, E. T., and Nomikos, G. G. (2005). A role for cannabinoid CB1 receptors in mood and anxiety disorders. Behav. Pharmacol. 16, 315-331. doi: 10.1097/00008877-200509000-00005

Witten, I. B., Steinberg, E. E., Lee, S. Y., Davidson, T. J., Zalocusky, K. A., Brodsky, M., et al. (2011). Recombinase-driver rat lines: tools, techniques and optogenetic application to dopamine-mediated reinforcement. Neuron 72, 721-733. doi: 10 . 1016/j.neuron.2011.10.028

Wymbs, N. F., and Grafton, S. T. (2009). Neural substrates of practice structure that support future off-line learning. J. Neurophysiol. 102, 2462-2476. doi: 10. 1152/jn.00315.2009

Yamamoto, D. J., Nelson, A. M., Mandt, B. H., Larson, G. A., Rorabaugh, J. M., Ng, C. M., et al. (2013). Rats classified as low or high cocaine locomotor responders: a unique model involving striatal dopamine transporters that predicts cocaine addiction-like behaviors. Neurosci. Biobehav. Rev. 37, 1738-1753. doi: 10.1016/j. neubiorev.2013.07.002

Yamasue, H., Abe, O., Suga, M., Yamada, H., Inoue, H., Tochigi, M., et al. (2008). Gender-common and -specific neuroanatomical basis of human anxiety-related personality traits. Cereb. Cortex 18, 46-52. doi: 10.1093/cercor/bhm030
Yehuda, R., and LeDoux, J. (2007). Response variation following trauma: a translational neuroscience approach to understanding PTSD. Neuron 56, 19-32. doi: 10.1016/j.neuron.2007.09.006

Yoshida, R., Ohkuri, T., Jyotaki, M., Yasuo, T., Horio, N., Yasumatsu, K., et al. (2010). Endocannabinoids selectively enhance sweet taste. Proc. Natl. Acad. Sci. U S A 107, 935-939. doi: 10.1073/pnas.0912048107

Youn, T., Lyoo, I. K., Kim, J. K., Park, H. J., Ha, K. S., Lee, D. S., et al. (2002). Relationship between personality trait and regional cerebral glucose metabolism assessed with positron emission tomography. Biol. Psychol. 60, 109-120. doi: 10. 1016/s0301-0511(02)00047-9

Zahn-Waxler, C., Shirtcliff, E. A., and Marceau, K. (2008). Disorders of childhood and adolescence: gender and psychopathology. Annu. Rev. Clin. Psychol. 4, 275303. doi: 10.1146/annurev.clinpsy.3.022806.091358

Zakharova, E., Wade, D., and Izenwasser, S. (2009). Sensitivity to cocaine conditioned reward depends on sex and age. Pharmacol. Biochem. Behav. 92, 131-134. doi: 10.1016/j.pbb.2008.11.002

Zoratto, F., Fiore, M., Ali, S. F., Laviola, G., and Macrì, S. (2013). Neonatal tryptophan depletion and corticosterone supplementation modify emotional responses in adult male mice. Psychoneuroendocrinology 38, 24-39. doi: 10 . 1016/j.psyneuen.2012.04.015

Conflict of Interest Statement: The authors declare that the research was conducted in the absence of any commercial or financial relationships that could be construed as a potential conflict of interest.

Received: 01 July 2014; accepted: 28 November 2014; published online: 22 December 2014.

Citation: Laricchiuta D and Petrosini L (2014) Individual differences in response to positive and negative stimuli: endocannabinoid-based insight on approach and avoidance behaviors. Front. Syst. Neurosci. 8:238. doi: 10.3389/fnsys.2014.00238 This article was submitted to the journal Frontiers in Systems Neuroscience.

Copyright (C) 2014 Laricchiuta and Petrosini. This is an open-access article distributed under the terms of the Creative Commons Attribution License (CC BY). The use, distribution and reproduction in other forums is permitted, provided the original author(s) or licensor are credited and that the original publication in this journal is cited, in accordance with accepted academic practice. No use, distribution or reproduction is permitted which does not comply with these terms. 